\title{
journal
}

\section{Novel Insights into Electrical Transport Mechanism in Ionic- Polaronic Glasses}

\begin{tabular}{|r|l|}
\hline Journal: & Journal of the American Ceramic Society \\
\hline Manuscript ID & JACERS-40446 \\
\hline Manuscript Type: & Article \\
\hline Complete List of Authors: & $\begin{array}{l}\text { Nikolic, Juraj; Ruder Boskovic Institute, Division of Materials Chemistry } \\
\text { Pavic, Luka; Ruder Boskovic Institute, Division of Materials Chemistry } \\
\text { Santic, Ana; Rudjer Boskovic Institute, Division of Materials Chemistry } \\
\text { Mosner, Petr; University of Pardubice, Faculty of chemical technology; } \\
\text { Koudelka, Ladislav; University of Pardubice, General and Inorganic } \\
\text { Chemistry; } \\
\text { Pajić, Damir ; Sveuciliste u Zagrebu Fizicki odsjek } \\
\text { Mogus-Milankovic, Andrea; Ruder Boskovic Institute, Division of Materials } \\
\text { Chemistry }\end{array}$ \\
\hline Keywords: & \begin{tabular}{l} 
electrical conductivity, glass, impedance spectroscopy, phosphates \\
\hline
\end{tabular} \\
\hline
\end{tabular}




\title{
Novel Insights into Electrical Transport Mechanism in Ionic-Polaronic Glasses
}

\author{
Juraj Nikolić ${ }^{1}$, Luka Pavić ${ }^{1}$, Ana Šntić ${ }^{1}$, Petr Mošner ${ }^{2}$, Ladislav Koudelka ${ }^{2}$, Damir Pajić ${ }^{3}$, Andrea \\ Moguš-Milanković ${ }^{1 *}$ \\ ${ }^{I}$ Division of Materials Chemistry, Ruđer Bošković Institute, 10000 Zagreb, Croatia \\ ${ }^{2}$ Department of General and Inorganic Chemistry, University of Pardubice, Faculty of Chemical Technology, 53210 \\ Pardubice, Czech Republic \\ ${ }^{3}$ Department of Physics, Faculty of Science, University of Zagreb, 10000 Zagreb, Croatia
}

\begin{abstract}
Transformation of electrical transport from ionic to polaronic in glasses, which are a potential class of new cathode materials, has been investigated in four series containing $\mathrm{WO}_{3} / \mathrm{MoO}_{3}$ and $\mathrm{Li}^{+} / \mathrm{Na}^{+}$ ions, namely: $\quad \mathrm{XWO}_{3}-(30-0.5 \mathrm{x}) \mathrm{Li}_{2} \mathrm{O}-(30-0.5 \mathrm{x}) \mathrm{ZnO}-40 \mathrm{P}_{2} \mathrm{O}_{5}, \quad \mathrm{xWO}_{3}-(30-0.5 \mathrm{x}) \mathrm{Na}_{2} \mathrm{O}-(30.5 \mathrm{x}) \mathrm{ZnO}-$ $40 \mathrm{P}_{2} \mathrm{O}_{5}, \quad x \mathrm{xoO}_{3}-(30-0.5 \mathrm{x}) \mathrm{Li}_{2} \mathrm{O}-(30-0.5 \mathrm{x}) \mathrm{ZnO}-40 \mathrm{P}_{2} \mathrm{O}_{5}$, and $\mathrm{xMoO}_{3}-(30-0.5 \mathrm{x}) \mathrm{Na}_{2} \mathrm{O}-(30-0.5 \mathrm{x}) \mathrm{ZnO}-$ $40 \mathrm{P}_{2} \mathrm{O}_{5}, \quad 0 \leq \mathrm{x} \leq 60,(\mathrm{~mol} \%)$. This study reports a detailed analysis of the role of structural modifications and its implications on the origin of electrical transport in these mixed ionic-polaron glasses. Raman spectra show the clustering of $\mathrm{WO}_{6}$ units by the formation of $\mathrm{W}-\mathrm{O}-\mathrm{W}$ bonds in glasses with high $\mathrm{WO}_{3}$ content while the coexistence of $\mathrm{MoO}_{4}$ and $\mathrm{MoO}_{6}$ units is evidenced in glasses containing $\mathrm{MoO}_{3}$ with no clustering of $\mathrm{MoO}_{6}$ octahedra. Consequently, DC conductivity of tungstate glasses either with $\mathrm{Li}^{+}$or $\mathrm{Na}^{+}$exhibits a transition from ionic to polaronic showing a minimum at about $20-30 \mathrm{~mol} \%$ of $\mathrm{WO}_{3}$ as a result of ionic-polaron interaction followed by a sharp increase for six orders of magnitude as $\mathrm{WO}_{3}$ content increases. The formation of $\mathrm{WO}_{6}$ clusters involved in W-O-W linkages for tungsten glasses plays a key role in significant increase of DC conductivity. On the other hand, DC conductivity is almost constant for glasses containing $\mathrm{MoO}_{3}$
\end{abstract}


suggesting an independent ionic and polaronic transport pathways for glasses containing 10-50 $\mathrm{mol} \% \mathrm{MoO}_{3}$.

KEYWORDS: Mixed ion-polaron glasses, Ionic and polaronic conductivity, Electrical transport mechanisms, Impedance spectroscopy

Corresponding Author: A. Moguš-Milanković, Address: Ruđer Bošković Institute, 10000 Zagreb, Croatia, Tel.:++385-1-4561-149; E-mail address: mogus@irb.hr; member of The American Ceramic Society. 


\section{Introduction}

Glasses are commonly formed by mixing glass forming oxides with modifier metal oxides. Transition metal oxides such as $\mathrm{MoO}_{3}$ and $\mathrm{WO}_{3}$ along with alkali oxides as $\mathrm{Li}_{2} \mathrm{O}$ or $\mathrm{Na}_{2} \mathrm{O}$ are able to form glasses with $\mathrm{P}_{2} \mathrm{O}_{5}$ in a broad compositional range that are mixed electronic-ionic conductors which are of interest as potential cathode materials in solid state batteries, memory switching and optical switching devices. ${ }^{1,2}$ From the point of view of large scale applications of solid state batteries the high cost and limited availability of lithium resources becomes a serious problem. On the other hand, sodium-ion batteries have generated great interest as an attractive alternative to lithium ones. Therefore, compositions containing $\mathrm{MoO}_{3}$ and $\mathrm{WO}_{3}$ as well as $\mathrm{Li}_{2} \mathrm{O}$ and $\mathrm{Na}_{2} \mathrm{O}$ in phosphate glass systems might be identified as new positive electrode materials.

Introduction of a divalent oxide, such as $\mathrm{ZnO}$, leads to an improvement in the mechanical and thermal expansion properties by increasing the bond strength in the phosphate glass network. This increase in strength is related to the shortening of the bonds which in turns enhances the compactness of phosphate structure. ${ }^{3-5}$

Molybdenum-phosphate and tungsten-phosphate glasses belong to those groups of glasses where $\mathrm{MoO}_{3}$ and $\mathrm{WO}_{3}$ show an exceptional ability of incorporation into phosphate network. It has been shown that large amounts of $\mathrm{MoO}_{3}$ and $\mathrm{WO}_{3}$, even up $60 \mathrm{~mol} \%$, can be easily added without devitrification. ${ }^{6-8}$ Besides that, both molybdenum-phosphate and tungsten-phosphate glasses exhibit interesting electrochromic properties and high polaronic conductivity that makes them prospective glasses for various electronic and optical devices. It is well known that in these glasses tungsten or molybdenum ions exist in two valence states $^{9}$ and in such systems the electronic conduction takes place by small polaron hoping from lower to higher valence state. ${ }^{10}$ On the other hand, the exchange of $\mathrm{MoO}_{3}$ and $\mathrm{WO}_{3}$ by $\mathrm{Li}_{2} \mathrm{O}$ in phosphate glasses causes changes in the nature of the electrical 
conductivity. ${ }^{11,12}$ At low $\mathrm{Mo} / \mathrm{P}$ and $\mathrm{W} / \mathrm{P}$ ratio, the $\mathrm{DC}$ conductivity is dominantly ionic whereas with increasing $\mathrm{MoO}_{3}$ and $\mathrm{WO}_{3}$ content, conductivity becomes predominantly electronic.

Moreover, in some mixed ion-polaron glasses the variation of conductivity with the glass composition suggests an effect of ion-polaron interactions. This concept was first proposed by Bazan et al. more than two decades ago. ${ }^{13}$ The authors showed that the substitution of $\mathrm{WO}_{3}$ by $\mathrm{Li}_{2} \mathrm{O}$ in $\mathrm{Li}_{2} \mathrm{O}-\mathrm{WO}_{3}-\mathrm{P}_{2} \mathrm{O}_{5}$ glasses results in a deep minimum in electrical conductivity which can be attributed to strong coupling of lithium ions and polarons which forms a neutral cation-polaron pairs. The mobility of these neutral entities is not involved in net displacement of electrical charge and therefore does not contribute to the electrical conductivity. ${ }^{11-13}$ However, in the interpretation of these results several crucial parameters for mixed ion-polaron transport, such as fraction of tungsten ions in different valence states and the role of glass structure have not been discussed.

Further, in the more recent papers ${ }^{11,14}$ similar effects in different glass systems have been reported. In these studies a special attention was paid to the determination of various factors that might influence complex ion-polaron transport for example, number density of ions vs polarons, their mobility as well as specific structural features of the glass network. While the transition between predominantly ionic and predominantly polaronic conduction has been well evidenced in these glass systems containing alkali oxides and transition metal oxides, the existence of mutual interactions between ions and polarons in oxide glasses is still a matter of debate.

In particular, recent studies have reported that there is no clear correlation between variation of electronic or mixed ionic-electronic conductivity as a function of the addition of $\mathrm{MoO}_{3}$ or $\mathrm{Li}_{2} \mathrm{O} / \mathrm{Na}_{2} \mathrm{O} .{ }^{11,12}$ These studies have demonstrated that the non-linear behavior of $\mathrm{Mo}^{5+} / \mathrm{Mo}_{\text {tot }}$ ratio and the presence of a maximum are related to the structural changes in these glasses. However, the influence of structure as well as changes in molybdenum and tungsten valence states on the nature of electrical conductivity in mixed ion-polaron glasses has not been completely resolved. 
Structure of molybdenum and tungsten-phosphate glasses is well documented in the literature. Most of the structural studies are related to the binary ${ }^{15-17}$ and ternary glass systems. ${ }^{8,18,19}$ The structural network evolution of the binary $\mathrm{NaPO}_{3}-\mathrm{WO}_{3}$ and $\mathrm{NaPO}_{3}-\mathrm{MoO}_{3}$ systems has been investigated using high-resolution solid state NMR as well as Raman spectroscopy. ${ }^{16,17}$ It was found that the addition of tungsten or molybdenum to $\mathrm{NaPO}_{3}$ transforms the phosphate network by incorporation of various $\mathrm{WO}_{n}$ or $\mathrm{MoO}_{n}$ polyhedra into the phosphate structure. Structural studies also reported an irregular variation of glass transition temperature, $T_{\mathrm{g}}$, with increasing $\mathrm{WO}_{3}$ or $\mathrm{MoO}_{3}$ content. ${ }^{16,20,21}$

In several recently published papers the glass-forming ability and structure of series of $\mathrm{ZnO}$ $\mathrm{WO}_{3}-\mathrm{P}_{2} \mathrm{O}_{5}$ and $\mathrm{PbO}-\mathrm{MoO}_{3}-\mathrm{P}_{2} \mathrm{O}_{5}$ glasses have been reported. ${ }^{20,21}$ The structural studies of these series of glasses obtained by Raman and ${ }^{31} \mathrm{P}$ NMR spectroscopy have shown that at higher $\mathrm{WO}_{3}$ content tungsten atoms are predominantly octahedrally coordinated whereas at high $\mathrm{ZnO}$ content the coexistence of $\mathrm{WO}_{4}$ and $\mathrm{WO}_{6}$ units is present. ${ }^{20}$ On the other hand, in $\mathrm{PbO}-\mathrm{MoO}_{3}-\mathrm{P}_{2} \mathrm{O}_{5}$ glasses with high phosphate and molybdenum content $\mathrm{MoO}_{4}$ tetrahedra were formed. ${ }^{21}$

Detailed understanding of the electrical transport mechanism in the mixed electronic-ionic glasses calls for deep analysis. The challenge now is how to expand our knowledge to the more complex mixed ion-polaron glass systems. Our intention in the current work is to investigate changes of electrical transport mechanisms in four families of glasses with general composition, $\mathrm{Li}_{2} \mathrm{O}-\mathrm{ZnO}$ $\mathrm{P}_{2} \mathrm{O}_{5}-\mathrm{WO}_{3}, \quad \mathrm{Li}_{2} \mathrm{O}-\mathrm{ZnO}-\mathrm{P}_{2} \mathrm{O}_{5}-\mathrm{MoO}_{3}, \quad \mathrm{Na}_{2} \mathrm{O}-\mathrm{ZnO}-\mathrm{P}_{2} \mathrm{O}_{5}-\mathrm{WO}_{3}$ and $\mathrm{Na}_{2} \mathrm{O}-\mathrm{ZnO}-\mathrm{P}_{2} \mathrm{O}_{5}-\mathrm{MoO}_{3}$. The guiding principle is to examine the differences in glass structure due to the addition of $\mathrm{MoO}_{3}$ and $\mathrm{WO}_{3}$ and examine the influence on the ion and polaron transport in correlation to the local structure. Thus, the question arises how the replacement of $\mathrm{WO}_{3}$ and $\mathrm{MoO}_{3}$ by $\mathrm{Li}_{2} \mathrm{O}$ and $\mathrm{Na}_{2} \mathrm{O}$ along with reducing $\mathrm{ZnO}$ content affects the mobility of $\mathrm{Li}^{+}$and $\mathrm{Na}^{+}$ions as well as polaron-hopping in investigated glasses. The attractiveness of glass systems investigated from fundamental and 
applicative point of view lies in the fact that these glasses exhibit electrical properties as both solid electrolytes and electronic conductors. Therefore, it is of interest to reinforce the key idea of the tunability of two transport mechanisms and examine if they are correlated or independent.

\section{Experimental}

Four series of glasses in the quaternary systems:

A) $x \mathrm{WO}_{3}-(30-0.5 \mathrm{x}) \mathrm{Li}_{2} \mathrm{O}-(30-0.5 \mathrm{x}) \mathrm{ZnO}-40 \mathrm{P}_{2} \mathrm{O}_{5}$, with $\mathrm{x}=0,10,20,30,40,50,60(\mathrm{~mol} \%)$

B) $\mathrm{xWO}_{3}-(30-0.5 \mathrm{x}) \mathrm{Na}_{2} \mathrm{O}-(30-0.5 \mathrm{x}) \mathrm{ZnO}-40 \mathrm{P}_{2} \mathrm{O}_{5}$, with $\mathrm{x}=0,10,20,30,40,50,60(\mathrm{~mol} \%)$

C) $\mathrm{xMoO}_{3}-(30-0.5 \mathrm{x}) \mathrm{Li}_{2} \mathrm{O}-(30-0.5 \mathrm{x}) \mathrm{ZnO}-40 \mathrm{P}_{2} \mathrm{O}_{5}$, with $\mathrm{x}=0,10,20,30,40,50,60(\mathrm{~mol} \%)$

D) $\mathrm{xMoO}_{3}-(30-0.5 \mathrm{x}) \mathrm{Na}_{2} \mathrm{O}-(30-0.5 \mathrm{x}) \mathrm{ZnO}-40 \mathrm{P}_{2} \mathrm{O}_{5}$, with $\mathrm{x}=0,10,20,30,40,50,60(\mathrm{~mol} \%)$

with $\mathrm{MoO}_{3}$ and $\mathrm{WO}_{3}$ content varying from 10 to $60 \mathrm{~mol} \%$ were prepared by conventional meltquenching using analytical grade $\mathrm{Na}_{2} \mathrm{CO}_{3}$ or $\mathrm{Li}_{2} \mathrm{CO}_{3}, \mathrm{ZnO}, \mathrm{H}_{3} \mathrm{PO}_{4}, \mathrm{WO}_{3}$ or $\mathrm{MoO}_{3}$. $\mathrm{ZnO}$ content variation is needed in these glasses for charge neutrality. However, it is expected that $\mathrm{Zn}^{2+}$ itself does not contribute significantly to the electrical transport properties but its concentration plays a role in compactness of the glass structure. ${ }^{5}$

The homogenized starting mixtures were slowly heated from room temperature up to $873 \mathrm{~K}$ keeping the maximum temperature for 2 hours to remove water. After that, the reaction mixtures were heated up to $1273-1623 \mathrm{~K}$, depending on glass composition, in a platinum crucible with a lid. The melt was held at maximum temperature for 20 minutes and then poured into a preheated graphite mold. Obtained glasses were then transferred to the annealing furnace for 2 hours at a temperature $5 \mathrm{~K}$ below their glass transition temperature, $T_{g}$, and then cooled to room temperature. The volatilization losses checked by weighting were not significant, hence the batch compositions can be considered as reflecting actual compositions. The amorphous character of the glasses was confirmed by X-ray diffraction. 
The glass density, $\rho$, of the bulk samples was determined using the Archimedes' method using toluene as the immersion liquid. The glass transition temperature, $T_{\mathrm{g}}$, was measured on bulk samples with dimensions of $25 \times 5 \times 5 \mathrm{~mm}^{3}$ using dilatometer DIL 402 PC (Netzsch), where $T_{\mathrm{g}}$ was determined from the change in the slope of the elongation vs. temperature plot. Dilatometric measurements were carried out in air at the heating rate of $3 \mathrm{~K} \mathrm{~min}^{-1}$.

The Raman spectra were recorded on bulk samples at room temperature using a Horiba-Jobin Yvon LaBRam HR spectrometer. The spectra were recorded in back-scattering geometry under excitation with Nd-YAG laser radiation $(532 \mathrm{~nm})$ at a power of $12 \mathrm{~mW}$ on the sample. The spectral slit width was $1.5 \mathrm{~cm}^{-1}$ and the total integration time was 50 seconds.

The electron spin resonance (ESR) spectra of powdered glassy samples were measured at ambient temperature at X-band microwave frequency $(\sim 9.5 \mathrm{GHz})$ using a spectrometer ESR 221 Magnettech Berlin. Using $\mathrm{Mn}^{2+}$ standard the spin concentration was determined for all measured samples and the ratio of $\mathrm{Mo}^{5+} / \mathrm{Mo}_{\text {tot }}$ was calculated from the obtained data.

The fraction of tungsten ions in different valence states, $\mathrm{W}^{5+} / \mathrm{W}_{\text {tot }}$, was determined from the temperature dependence of magnetization, measured from $2 \mathrm{~K}$ to $300 \mathrm{~K}$ in constant magnetic field of $0.1 \mathrm{~T}$. This is possible due to the magnetic moment of single uncoupled electron sitting on the $\mathrm{W}^{5+}$ ion, whereas the $\mathrm{W}^{6+}$ ion is diamagnetic. Small amount of the paramagnetic ions in studied materials is possible to determine very precisely from magnetization measurements due to unique sensitivity of the MPMS5 SQUID magnetometer. However, in order to get the accurate results the measurements are performed with additional precaution needed to avoid any magnetic contamination, mounting the sample without grease as well as to maintain a stable temperature during measurement of each point.

The temperature dependence of magnetic susceptibility $\chi(T)$ (mass magnetization divided by magnetic field) was fitted very well with the Curie law: 


$$
\chi(T)=\frac{N_{A} \mu_{B}^{2} g^{2} S(S+1) P}{3 M k_{b} T}+\chi_{d}
$$

where $N_{\mathrm{A}}$ is the Avogadro number, $\mu_{\mathrm{B}}$ is the Bohr magneton, $k_{\mathrm{B}}$ is the Boltzmann constant, $g=1.71$ is the gyromagnetic factor obtained from the EPR measurement of the investigated glass, spin $\mathrm{S}=1 / 2$ determined from the single electron on every $\mathrm{W}^{5+}$ ion, $M$ is the molar mass of the glass reduced by the $P / 2$ times the molar mass of oxygen atom, $P$ is the free parameter fitted very reliably and $\chi_{\mathrm{d}}$ is the additive constant included in describing the diamagnetic contribution of the glass. At the end, fraction of $\mathrm{W}^{5+}$ ions in the total number of tungsten ions was determined dividing $P$ by the stoichiometric fraction of $\mathrm{WO}_{3}$ in glass. Errors of the obtained values are less than $1 \%$ and the fraction of tungsten ions values are given in Tables 1 and 2.

Annealed samples for electrical property measurements were polished with SiC polishing papers. Gold electrodes, $7 \mathrm{~mm}$ in diameter, were sputtered onto both sides of $1 \mathrm{~mm}$ thick disks using Sputter Coater SC7620. Electrical properties were obtained by measuring complex impedance using an impedance analyzer (Novocontrol Alpha-AN Dielectric Spectrometer) over the frequency range from $0.01 \mathrm{~Hz}$ to $1 \mathrm{MHz}$ and in the temperature range from 303 to $513 \mathrm{~K}$. The temperature was controlled to an accuracy of $\pm 0.2 \mathrm{~K}$.

\section{Results}

\subsection{Thermal behavior}

Starting glasses $30 \mathrm{Li}_{2} \mathrm{O}-30 \mathrm{ZnO}-40 \mathrm{P}_{2} \mathrm{O}_{5}(\mathrm{Li}-0 \mathrm{TMO})$ and $30 \mathrm{Na}_{2} \mathrm{O}-30 \mathrm{ZnO}-40 \mathrm{P}_{2} \mathrm{O}_{5}$ (Na-0TMO) were clear and transparent. Glasses containing $\mathrm{WO}_{3}$ were of blue color, which deepened with increasing $\mathrm{WO}_{3}$ content whereas glasses containing $\mathrm{MoO}_{3}$ induce an intense green color. In Tables 1 and 2 the glass compositions together with the experimental values of glass densities, $\rho$, glass transition temperatures, $T_{\mathrm{g}}$, and fractions of $\mathrm{W}^{5+} / \mathrm{W}_{\text {tot }}$ and $\mathrm{Mo}^{5+} / \mathrm{Mo}_{\text {tot }}$ are presented. 
Figure 1(a-d) compares the dependence of $T_{\mathrm{g}}$ and $\rho$ on the $\mathrm{WO}_{3}$ and $\mathrm{MoO}_{3}$ contents for all glasses in the present study. It can be seen that both $T_{\mathrm{g}}$ and $\rho$ increase, $T_{\mathrm{g}}$ : from 579 to $741 \mathrm{~K}$ for Li-W and from 579 to $793 \mathrm{~K}$ for Na-W glasses. However, a step in increase of $T_{\mathrm{g}}$ for Li-W and Na-W glasses between $30-40$ mol\% of $\mathrm{WO}_{3}$ was observed. For Li-Mo and Na-Mo glasses the $T_{\mathrm{g}}$ almost linearly increases in entire compositional range whereas $\rho$ remains constant at about $3.10 \mathrm{~g} \mathrm{~cm}^{-3}$. The increase in $T_{\mathrm{g}}$ for all glasses with increasing $\mathrm{WO}_{3}$ and $\mathrm{MoO}_{3}$ suggests an increase in thermal stability against crystallization as a result of stronger bonding in these glasses.

\subsection{Structural Analysis}

Raman spectra for lithium series of glasses containing $\mathrm{WO}_{3}$ and $\mathrm{MoO}_{3}$ are shown in Figure 2(ab). For the Na-W and Na-Mo series of glasses the evolution of the Raman spectra is presented in Supplemental Materials, Figure S1. Raman spectrum of the starting glass Li-0TMO is characteristic for polyphosphate structure. ${ }^{22,23}$ Dominant bands at 1165 and $705 \mathrm{~cm}^{-1}$ are associated with the symmetrical stretching vibration of non-bridging oxygens and symmetrical stretching vibration of bridging oxygens in $\mathrm{Q}^{2}$ phosphate units, respectively. A weak band at $1238 \mathrm{~cm}^{-1}$ attributed to the asymmetric stretching vibration of non-bridging oxygens, $\mathrm{P}_{-} \mathrm{O}^{-}$, in $\mathrm{Q}^{2}$ units along with the band at 1045 and $1123 \mathrm{~cm}^{-1}$ related to the vibration in $\mathrm{Q}^{1}$ units are present in this lithium zinc phosphate glass. $^{22-25}$ However, barely detectable band at about $1000 \mathrm{~cm}^{-1}$ is associated with $\mathrm{Q}^{0}$ phosphate units. Generally, it should be concluded that the $\mathrm{Q}^{2}$ and $\mathrm{Q}^{1}$ phosphate units are the most dominant units present in this glass.

With the addition of $\mathrm{WO}_{3}$ to the lithium-zinc phosphate glass, Figure 2(a), a new strong band appears in the Raman spectra at $971 \mathrm{~cm}^{-1}$ with a shoulder at $914 \mathrm{~cm}^{-1}$. Raman bands and their assignments are presented in Supplemental Materials, Table S1. These bands are ascribed to the vibration of $\mathrm{W}=\mathrm{O}$ or $\mathrm{W}-\mathrm{O}^{-}$terminal bonds in $\mathrm{WO}_{6}$ octahedra incorporated into glass structure. ${ }^{16,20}$ With increasing $\mathrm{WO}_{3}$ content up to $60 \mathrm{~mol} \%$ maximum of the dominant band shifts to $993 \mathrm{~cm}^{-1}$ 
whereas its shoulder decreases in intensity. It is worth mentioning that the shift to higher wavenumber is related to the deformation of $\mathrm{WO}_{6}$ octahedra. Also, the presence of high frequency band at $993 \mathrm{~cm}^{-1}$ suggests that the terminal $\mathrm{W}=\mathrm{O}$ is present in entire compositional range.

For compositions containing more than $20 \mathrm{~mol} \%$ of $\mathrm{WO}_{3}$ a weak band at $855 \mathrm{~cm}^{-1}$ appears and increases in intensity at higher $\mathrm{WO}_{3}$ content. This band is associated with the W-O stretching vibrations within W-O-W bond in tungsten clusters. ${ }^{16,20}$ Vibrational bands of phosphate units at 1165 and $705 \mathrm{~cm}^{-1}$ decrease in their intensity with increasing $\mathrm{WO}_{3}$ content partly due to a high scattering cross-section of tungsten units.

Evolution of Raman spectra of Li-Mo glasses, showed in Figure 2(b), is similar to the spectra of Li-W glasses at the first glance. However, some differences in glass structure are found. There is also a doublet of bands in the range of $800-1000 \mathrm{~cm}^{-1}$ with the strong band at $956 \mathrm{~cm}^{-1}$ and a shoulder at $912 \mathrm{~cm}^{-1}$ which can be ascribed to the vibration of $\mathrm{Mo}=\mathrm{O}$ or $\mathrm{Mo}-\mathrm{O}^{-}$terminal bonds in $\mathrm{MoO}_{6}$ octahedra present in the glass structure. ${ }^{17,26}$

The decrease in the strength of vibrational bands of phosphate units at 1165 and $705 \mathrm{~cm}^{-1}$ is faster than at the analogous $\mathrm{WO}_{3}$ glasses. Further, for $\mathrm{Li}-40 \mathrm{~W}$ and $\mathrm{Li}-40 \mathrm{Mo}$ glasses the deconvolution of Raman spectra, presented in Supplemental Materials, Figure S2, clearly shows that at high $\mathrm{WO}_{3}$ content in $\mathrm{Li}-\mathrm{W}$ glasses the bands associated with $\mathrm{Q}^{2}$ and $\mathrm{Q}^{1}$ phosphate units are still visible whereas for glasses containing more than $30 \mathrm{~mol} \%$ of $\mathrm{MoO}_{3}$ in Li-Mo glasses the intensity of these bands are very weak. With further increasing $\mathrm{MoO}_{3}$ content maximum of the dominant band 956 $\mathrm{cm}^{-1}$ shifts to higher wavenumber up to $985 \mathrm{~cm}^{-1}$. A new band at $874 \mathrm{~cm}^{-1}$ grows steadily with increasing $\mathrm{MoO}_{3}$ content, which is attributed to the $\mathrm{MoO}_{4}$ tetrahedra. ${ }^{21,26}$ In lower frequency range a band at $393 \mathrm{~cm}^{-1}$ attributed to the Mo-O-P bonds appears. This band is observed in entire compositional range of Li-Mo glasses. On the other hand, the same band at about $385 \mathrm{~cm}^{-1}$ related to the $\mathrm{W}-\mathrm{O}-\mathrm{P}$ bonds in $\mathrm{Li}-\mathrm{W}$ glasses disappears as $\mathrm{WO}_{3}$ content increases. 


\subsection{Electrical Transport}

Conductivity spectra of Li-10W and Li-50W glasses are shown in Figure 3(a-b). Conductivity isotherms exhibit two features, plateau at low frequency that corresponds to the DC conductivity and dispersion at higher frequencies. At high temperatures and low frequencies for Li-10W glass containing $25 \mathrm{~mol} \%$ of $\mathrm{Li}_{2} \mathrm{O}$, a slight decrease in the conductivity was observed. Such a behavior is associated with the electrode polarization. On the other hand, with increasing $\mathrm{WO}_{3}$ and decreasing $\mathrm{Li}_{2} \mathrm{O}$ content in Li-50W glass the conductivity spectra show well defined DC plateau characteristic for polaronic glasses without evidence of effects of blocking electrodes. Similar conductivity spectra are observed for Li-Mo as well as for Na-W and Na-Mo glasses.

Figure 4(a-d) shows a compositional dependence of DC conductivity at various temperatures for all four series of glasses. As is seen from Figure 4(a-d), the conductivity behavior of Li-W and NaW glasses is different than that of Li-Mo and Na-Mo glasses. Also, conductivity value of Li-0TMO glasses measured at $303 \mathrm{~K}$ is slightly lower, $1.95 \times 10^{-13}(\Omega \mathrm{cm})^{-1}$, then the value of $7.94 \times 10^{-13}(\Omega$ $\mathrm{cm})^{-1}$ for Na-0TMO, Table 3. It is possible that the mobility of $\mathrm{Li}^{+}$ions is hindered in predominantly metaphosphate structure since the $\mathrm{Li}^{+}$ions might be more tightly bound to the discrete non-bridging oxygens in anionic metaphosphate units in comparison to $\mathrm{Na}^{+}$ions. ${ }^{25,27}$

Addition of $\mathrm{WO}_{3}$ either to sodium or lithium zinc phosphate glasses induces variations in DC conductivity, Figure 4(a-b). The conductivity of Li-W glasses passes through a sharp minimum at approximately 20-30 mol\% of $\mathrm{WO}_{3}$, followed by an increase in conductivity for several orders of magnitude with increasing $\mathrm{WO}_{3}$ content. The indication of a slight minimum at about 30-40 mol\% of $\mathrm{WO}_{3}$ was observed for $\mathrm{Na}-\mathrm{W}$ glasses. The presence of $\mathrm{Na}_{2} \mathrm{O}$ produces a more gentle decrease in conductivity at $30 \mathrm{~mol} \%$ of $\mathrm{WO}_{3}$ and then exhibits a sharp increase reaching the highest value in conductivity for binary 40P-60W glass. This behavior suggests a changeover from predominantly ionic to predominantly polaronic conductivity. 
Figure 4(a-b) also shows that the minimum of DC conductivity for Li-W and Na-W glasses is influenced by temperature, and in particular it is observed that with increasing temperature the minimum becomes steeper at higher temperatures. This effect can be probably related to the relative mobility and number density of charge carriers: $\mathrm{Li}^{+}, \mathrm{Na}^{+}$ions and polarons, at higher temperatures.

Substantially different behavior of DC conductivity was obtained for Li-Mo and Na-Mo glasses as can be seen in Figure 4(c-d). In the entire compositional range in Li-Mo and Na-Mo glasses the DC conductivity is almost constant except for binary 40P-60Mo glass which does not contain any $\mathrm{Li}_{2} \mathrm{O}$ or $\mathrm{Na}_{2} \mathrm{O}$.

The changes in the dominant transport mechanism in the tungsten glass systems are clearly visible in the shape of the complex impedance plots, Figure 5(a-c). The complex impedance plot of glasses with predominantly ionic conductivity, such as Na-10W glass, exhibit a single impedance semicircle with characteristic low-frequency spur related to the electrode polarization, Figure 5(a).

On the other hand, glasses which exhibit significant contribution of polaronic conduction along with the ionic one show two semicircles in the impedance plot, Figure 5(b). Such a behaviour is found to be typical for mixed conduction in various materials where selectively blocking electrodes (e.g. blocking for one carrier and non-blocking for the other one) are used. ${ }^{28-33}$ In our study we applied gold electrodes for electrical measurements which are blocking for ions and non-blocking for polarons. Therefore, the high frequency semicircle observed for Na-50W glass is associated with the dielectric relaxation of the bulk, whereas the additional semicircle at lower frequencies refers to a chemical relaxation due to unblocked polaronic diffusion. ${ }^{32,33}$ Similarly the two impedance plots were obtained for Li-W glasses confirming similar behaviour.

It was shown that the shape of the low frequency impedance semicircle varies from the typical Warburg-type response (which gives a $45^{\circ}$ line in the complex plane representation) to perfect semicircle depending on the ratios of concentration of ionic and electronic charge carrier and their 
mobilities as well as electrode properties such selectivity and roughness. ${ }^{32,33}$ For Na-W and Li-W glasses which contained $\geq 40 \mathrm{~mol} \%$ and $\geq 30 \mathrm{~mol} \% \mathrm{WO}_{3}$, respectively, and thus exhibit significant polaronic contribution, the low frequency semicircle is depressed without a clear indication of Warburg-type diffusion. This result suggests relatively low polaron concentrations in comparison to ionic one, however yet large enough to increase the total conductivity of the glass.

It should be noted that the low-frequency semicircle can be easily mistaken for contact effects related to the roughness of the sample surface. However, in our case these effects have been completely eliminated because repeated polishing of the sample had no effect on the complex impedance plots of these glasses. As a matter of fact, the presence of two semicircles has its origin in the coexistence of two transport mechanisms, namely ionic and polaronic.

Furthermore, binary 40P-60W and 40P-60Mo glasses exhibit single impedance semicircle without any signature of electrode polarisation which is typical for purely polaronic conductors, Figure $5(\mathrm{c}) .^{28,32,33}$

An important factor which should be considered in this analysis is the fraction of tungsten and molybdenum ions in different valence states, $\mathrm{W}^{5+} / \mathrm{W}_{\text {tot }}$ and $\mathrm{Mo}^{5+} / \mathrm{Mo}_{\text {tot }}$, Figure 6 , Tables 1 and 2. For Li-W and Na-W glasses the $\mathrm{W}^{5+} / \mathrm{W}_{\text {tot }}$ increases, although in the range between 20 and $30 \mathrm{~mol} \%$ of $\mathrm{WO}_{3}$ almost constant values were observed while for Li-Mo and Na-Mo the fraction values of $\mathrm{Mo}^{5+} / \mathrm{Mo}_{\text {tot }}$ linearly increases except for Li-50Mo glass. It should be mentioned that the values of $\mathrm{W}^{5+} / \mathrm{W}_{\text {tot }}$ fraction for Li-W and $\mathrm{Na}-\mathrm{W}$ glasses are significantly lower than that for $\mathrm{Mo}^{5+} / \mathrm{Mo}_{\text {tot }}$ in $\mathrm{Li}^{-}$ Mo and Na-Mo glasses, Tables 1 and 2. This difference can be associated to the different redox potential of Mo and W, i.e. stronger reduction tendency of molybdenum causes higher proportion of reduced $\mathrm{Mo}^{5+}$ species in the present glasses. ${ }^{15}$ 
Going further in the interpretation of conductivity, the activation energy of DC conductivity, $\mathrm{E}_{\mathrm{DC}}$, for each sample in four series of glasses was determined from the slope of $\log \sigma_{D C} T$ vs. $1 / T$ using the equation:

$$
\sigma_{\mathrm{DC}} T=\sigma_{0}^{*} \exp \left(-E_{\mathrm{DC}} / \mathrm{k}_{\mathrm{B}} T\right)
$$

where $\sigma_{\mathrm{DC}}$ is the $\mathrm{DC}$ conductivity, $\sigma_{0}{ }^{*}$ is the pre-exponential factor, $\mathrm{k}_{\mathrm{B}}$ is the Boltzmann constant and $T$ is temperature. The Arrhenius plots of the DC conductivity, $\sigma_{\mathrm{DC}}$, from which activation energies for Li-W and Li-Mo glasses were calculated, are shown in Figure 7. The corresponding activation energy values for all glasses investigated are listed in Table 3.

Figure $8(\mathrm{a}-\mathrm{b})$ shows the compositional dependence of activation energies, $E_{\mathrm{DC}}$, and preexponential factor, $\sigma_{0}{ }^{*}$, for all glasses present in this study. As can be seen, the behavior of activation energies, $E_{\mathrm{DC}}$, for $\mathrm{Li}-\mathrm{W}$ and $\mathrm{Na}-\mathrm{W}$ glasses exhibits a steep decrease above $20 \mathrm{~mol} \%$ of $\mathrm{WO}_{3}$ for $\mathrm{Li}-\mathrm{W}$ and $30 \mathrm{~mol} \%$ of $\mathrm{WO}_{3}$ for $\mathrm{Na}-\mathrm{W}$ glasses whereas activation energies for Li-Mo and Na-Mo glasses just slightly change with addition of $\mathrm{MoO}_{3}$ content. It was expected that a decrease in DC conductivity is related to the increase in activation energy and vice versa. Figure 8 contrasts these predictions showing constant values for activation energy up to $20 \mathrm{~mol} \%$ of $\mathrm{WO}_{3}$ and up to $30 \mathrm{~mol} \%$ of $\mathrm{WO}_{3}$ in $\mathrm{Li}-\mathrm{W}$ and $\mathrm{Na}-\mathrm{W}$ glasses, respectively. This result suggests that in compositional range up to $20 \mathrm{~mol} \%$ and $30 \mathrm{~mol}^{\%}$ of $\mathrm{WO}_{3}$ for $\mathrm{Li}-\mathrm{W}$ and $\mathrm{Na}-\mathrm{W}$ glasses, respectively, the structure is almost same implying that the height of energy barriers is nearly the same. It should be mentioned that the pre-exponential factor, $\sigma_{0}{ }^{*}$, decreases in the region at $20 \mathrm{~mol} \%$ and $30 \mathrm{~mol} \%$ of $\mathrm{WO}_{3}$ for $\mathrm{Li}-\mathrm{W}$ and $\mathrm{Na}-\mathrm{W}$ series of glasses.

\section{Discussion}

The evolution of Raman spectra exhibits the transformation of phosphate network which includes shortening of metaphosphate and pyrophosphate chains and incorporation of $\mathrm{WO}_{n}$ and $\mathrm{MoO}_{n}$ 
polyhedra into phosphate structure, Figure 2(a-b) and Table S1. For glasses containing up to 20 mol\% of $\mathrm{WO}_{3}$ the structure consists of $\mathrm{PO}_{4}$ units in metaphosphate chains interlinked to $\mathrm{WO}_{\mathrm{n}}$ units in the glass network. Such a behavior is evidenced by the Raman bands at 1165 and $705 \mathrm{~cm}^{-1}$ confirming the presence of metaphosphate units in glass containing $20 \mathrm{~mol} \%$ of $\mathrm{WO}_{3}$, Figure 2 (a). Also, the Raman spectra show the cross-linkage between phosphate chains and tungsten units via PO-W connectivity. As previously reported, Raman spectra for glasses with higher $\mathrm{WO}_{3}$ content exhibit bands at 854 and $760 \mathrm{~cm}^{-1}$, for Li-50W glass, which are attributed to the asymmetric and symmetric stretching of $\mathrm{W}-\mathrm{O}-\mathrm{W}$ bonds interlinked in $\mathrm{WO}_{6}$ octahedra indicating formation of threedimensional clusters. Similar findings are reported by de Araujo et al. for $\mathrm{NaPO}_{3}-\mathrm{WO}_{3}$ glasses. ${ }^{16}$ They have shown that by the addition of $\mathrm{WO}_{3}$ two structural transformations can be separated. Initially, the addition of $\mathrm{WO}_{3}$ to $\mathrm{NaPO}_{3}$ forms $\mathrm{P}-\mathrm{O}-\mathrm{W}$ bonds which crosslinks phosphate chains in one-dimensional structure and transforms it into the thee-dimensional network of interconnected $\mathrm{PO}_{4}$ and $\mathrm{WO}_{6}$ polyhedra. ${ }^{16}$ On the other hand, in highly $\mathrm{WO}_{3}$-concentrated glasses structural studies indicated the formation of $\mathrm{WO}_{6}$ clusters as a result of the presence of $\mathrm{W}-\mathrm{O}-\mathrm{W}$ bonds. ${ }^{18,19}$ Since these glasses show specific photochromic and electrochromic properties it was also suggested that such highly polarizable clusters are responsible for non-linear and photochromic properties. ${ }^{34}$ In this connection it could be concluded that at high content of $\mathrm{WO}_{3}$ in $\mathrm{Li}-\mathrm{W}$ and $\mathrm{Na}-\mathrm{W}$ glasses, the $\mathrm{WO}_{6}$ octahedra form clusters involved in $\mathrm{W}-\mathrm{O}-\mathrm{W}$ bonding. Therefore, the observed slight step in $T_{\mathrm{g}}$ for glasses containing $\geq 40 \mathrm{~mol} \%$ of $\mathrm{WO}_{3}$ (Figure 1.) is probably directly correlated with the formation of such clusters.

Slightly different behavior was found in lithium molybdate-phosphate glasses. In accordance with the previously published papers ${ }^{17,21}$ bands at $956 \mathrm{~cm}^{-1}$ and $912 \mathrm{~cm}^{-1}$ that appeared in Raman spectra with the initial addition of $\mathrm{MoO}_{3}$ are related to the terminal Mo-O bonds with either four-, five- or six-coordinated Mo atoms. Such a behavior indicates an interconnection between the 
phosphorus and molybdenum by forming Mo-O-P bonds in this compositional region. Moreover, the intense band at $874 \mathrm{~cm}^{-1}$ detected for glass with higher $\mathrm{MoO}_{3}$ can be ascribed to the symmetric mode of tetrahedral $\mathrm{MoO}_{4}$ units present in the glass structure. The band at $874 \mathrm{~cm}^{-1}$ is close to the band at $870 \mathrm{~cm}^{-1}$ observed in the Raman spectrum of polycrystalline $\mathrm{PbMoO}_{4}{ }^{21}$ Thus comparing these two values, the presence of $\mathrm{MoO}_{4}$ tetrahedra in Li-Mo glass structures with higher $\mathrm{MoO}_{3}$ content $(40,50$ and $60 \mathrm{~mol} \%)$ is assumed. Also, shoulder which usually appears at lower wavenumber values at $840-850 \mathrm{~cm}^{-1}$ and corresponds to the Mo-O-Mo bond in the glass network was not evidenced in the Raman spectra of glasses containing high $\mathrm{MoO}_{3}$. Small band observed at 380-399 $\mathrm{cm}^{-1}$, according to Šubčik et al. ${ }^{26}$ present in the Raman spectra of molybdate-phosphate glasses, is attributed to the Mo-O-P bonds. Since this band slightly increases in intensity and is present in entire compositional range it seems that formed Mo-O-P connectivity stabilizes glass structure which is observed in the increase of $T_{\mathrm{g}}$ in entire compositional region, Figure 1 . On the basis of all these observations it should be concluded that with relatively high $\mathrm{MoO}_{3}$ content and constant $\mathrm{P}_{2} \mathrm{O}_{5}$ at $40 \mathrm{~mol} \%$, the dominant molybdenum coordination is four suggesting that there is no clustering of molybdate units via Mo-O-Mo bonds. However, it should be noted that along with $\mathrm{MoO}_{4}$ units the octahedrally coordinated molybdenum, $\mathrm{MoO}_{6}$, are also present in these glass structures as can be seen in Raman spectra, Figure 2. Similar findings are reported for $\mathrm{PbO}-\mathrm{MoO}_{3}$ $\mathrm{P}_{2} \mathrm{O}_{5}$ glasses where at high phosphate and high molybdenum content tetrahedrally coordinated molybdenum are formed. ${ }^{21}$ Therefore, depending on composition, especially on phosphate content, the glass network of Li-Mo glasses consists of both $\mathrm{MoO}_{4}$ tetrahedra and $\mathrm{MoO}_{6}$ octahedra. This is consistent with the solid state ${ }^{95} \mathrm{Mo} \mathrm{NMR}$ data obtained for $\mathrm{NaPO}_{3}-\mathrm{MoO}_{3}$ glasses showing two main broad resonances which are assigned to $\mathrm{MoO}_{6}$ and $\mathrm{MoO}_{4}$ units. ${ }^{17}$ Moreover, this study reports that with increasing $\mathrm{MoO}_{3}$ content a significant amount of lower-coordinated Mo is present. 
Further, in Raman spectra bands at 839 and $781 \mathrm{~cm}^{-1}$ that correspond to the Mo-O-Mo bonds are observed in binary 40P-60Mo glass. This indicates that with high $\mathrm{MoO}_{3}$ content these bonds appear in the glass network but does not imply clustering of $\mathrm{MoO}_{6}$ octahedra.

In view of the above mentioned modifications of glass structure, the variation in conductivity can be interpreted. Behavior of the DC conductivity in Li-W and $\mathrm{Na}-\mathrm{W}$ glasses is different in comparison to Li-Mo and Na-Mo glasses.

The pronounced decrease in DC conductivity up to $20 \mathrm{~mol}^{\%}$ of $\mathrm{WO}_{3}$ in $\mathrm{Li}-\mathrm{W}$ glasses is probably due to both a decrease of $\mathrm{Li}_{2} \mathrm{O}$ content from 30 to $20 \mathrm{~mol} \%$ and tight linkage of $\mathrm{Li}^{+}$ions to the terminal non-bridging oxygens in more depolymerized phosphate units, which reduces its mobility. On the other hand, $\mathrm{Na}^{+}$ions having lower electronegativity (0.9) if compared to $\mathrm{Li}^{+}$ions (1.0) and bigger size cause weaker bonding to the phosphate network. In this case, the addition of $\mathrm{WO}_{3}$ in the compositional range up to $30 \mathrm{~mol} \%$ of $\mathrm{WO}_{3}$ shows almost constant conductivity. There are two possible reasons for such a behavior. One is related to the increase of the mobility of $\mathrm{Na}^{+}$ions because of the depolymerization of phosphate chains which facilitates ionic transport and the other is an addition of $\mathrm{WO}_{3}$ which increases a polaronic contribution that has a compensating effect on the decrease in the concentration of mobile ions. In other ways, the interaction between ions and polarons in compositional region of $30-40 \mathrm{~mol} \%$ of $\mathrm{WO}_{3}$ content in $\mathrm{Na}-\mathrm{W}$ glasses produces a minimum. Further addition of $\mathrm{WO}_{3}$ content sharply increases $\mathrm{DC}$ conductivity at $303 \mathrm{~K}$ by almost six orders of magnitude for both Na-W and Li-W glasses. Such a behavior is directly related to the structural modifications observed with increasing $\mathrm{WO}_{3}$ content as a result of the formation of clusters of $\mathrm{WO}_{6}$ octahedra in Li-W and Na-W glass network.

At high $\mathrm{WO}_{3}$ content clusters formed of $\mathrm{WO}_{6}$ octahedra involved in $\mathrm{W}-\mathrm{O}-\mathrm{W}$ bonds facilitate the mobility of polarons. Therefore, enhanced transport through $\mathrm{W}^{5+}-\mathrm{O}-\mathrm{W}^{6+}-\mathrm{O}-\mathrm{W}^{5+}$ bonds in clusters suggest easier pathways for electrons resulting in a rapid increase of DC conductivity. 
In addition, the two semicircles observed in the impedance plots of Li-40W and Na-40W glasses confirm the coexistence of two transport mechanisms: at higher frequencies mixed ionic-polaronic conduction in bulk of glass, and polaronic conduction at lower frequencies, Figure 5. However, it is fascinating that two semicircles were obtained just for tungsten glasses at higher $\mathrm{WO}_{3}$ content suggesting a significantly high polaronic contribution to the total conductivity.

As mentioned earlier, essentially different behavior of DC conductivity was found in Li-Mo and Na-Mo series of glasses, Figure 4(c-d). In compositional region from 0 to $50 \mathrm{~mol} \%$ of $\mathrm{MoO}_{3}, \mathrm{DC}$ conductivity is almost constant. However, there is a slight change in the conductivity of Li-Mo glasses observed at $303 \mathrm{~K}$. Structural transformations by the addition of $\mathrm{MoO}_{3}$ to the lithium zinc phosphate glass might contribute to the conductivity in two different ways, in the region of lower $\mathrm{MoO}_{3}$ content up to $20 \mathrm{~mol} \%$ and higher, above $30 \mathrm{~mol} \%$. The addition of 10 and $20 \mathrm{~mol} \%$ of $\mathrm{MoO}_{3}$ increases DC conductivity slightly. This can be explained by the changes in the glass structure as the results of faster depolymerization of $\mathrm{Q}^{2}$ and $\mathrm{Q}^{1}$ phosphate units as $\mathrm{Li}_{2} \mathrm{O}$ is replaced by $\mathrm{MoO}_{3}$ in this phosphate network. Thus, it can be assumed that the $\mathrm{MoO}_{n}$ polyhedra inserted into phosphate chains favor the release of $\mathrm{Li}^{+}$ions linked to non-bringing oxygens in depolymerized phosphate network. When sufficient $\mathrm{Li}^{+}$ions are present at low $\mathrm{MoO}_{3}$ content, the mobility of free cations is probably greater than the motion of polarons which leads to discrete increase in dominant ionic conductivity. This result implies a different behavior of DC conductivity with addition of $\mathrm{MoO}_{3}$ when compared to the $\mathrm{WO}_{3}$ in the same compositional region.

With further increase of $\mathrm{MoO}_{3}$ and decrease of $\mathrm{Li}_{2} \mathrm{O}$ content reduction of ionic conductivity is expected. At the same time, the polaronic contribution to the total conductivity is expected to increase. However, since no systematic increase is observed in the compositional range between 30 to $40 \mathrm{~mol} \%$ of $\mathrm{MoO}_{3}$ content, it is possible that the pathways for polaron transport is discontinuous. Since the electron transfer process is related to the $\mathrm{Mo}^{5+}-\mathrm{O}-\mathrm{Mo}^{6+}$ bonds, it seems likely that the 
weaker connection of molybdenum units diminishes the electron mobility. Hence, a realistic view to take is that both ionic and electronic conduction occur simultaneously. However, their pathways are probably independent of each other.

Further, moving to the structural modifications of Li-Mo and Na-Mo glasses it is evidenced that there is no formation of clusters of $\mathrm{MoO}_{6}$ octahedra interconnected by Mo-O-Mo bonds at high $\mathrm{MoO}_{3}$ content, Figure 2. Thus, the addition of $\mathrm{MoO}_{3}$ in entire compositional range produces $\mathrm{P}-\mathrm{O}$ Mo linkages by incorporation of $\mathrm{MoO}_{3}$ into phosphate structure forming a three-dimensional glass network. Such a stable glass structure allows transport of ions and polarons through the ionic and polaronic pathways independently.

In order to gain a complete picture of the difference in the structural modifications between $\mathrm{WO}_{3}$ and $\mathrm{MoO}_{3}$ glasses few important findings should be considered. First, the incorporation of $\mathrm{MoO}_{\mathrm{n}}$ polyhedra into phosphate chains is much faster than that of $\mathrm{WO}_{\mathrm{n}}$ polyhedra in analogous glass systems. According to Raman spectra, Figure 2, initial addition of $\mathrm{MoO}_{3}$ to phosphate network produces Mo-O-P connectivity with molybdenum in octahedral coordination. Second, with further addition of $\mathrm{MoO}_{3}$ the tetrahedral units are clearly detected in Raman spectra as band at $889 \mathrm{~cm}^{-1}$ appeared. This band increases in intensity as $\mathrm{MoO}_{3}$ content increases while band at $839 \mathrm{~cm}^{-1}$ related to the Mo-O-Mo bonding appears just in purely polaronic glass containing $60 \mathrm{~mol} \%$ of $\mathrm{MoO}_{3}$, Figure2. In the latter glass along with $\mathrm{MoO}_{4}$ units, the Mo-O-Mo bonds are also evidenced. Therefore, this leads to the conclusion that Li-Mo and Na-Mo glasses are free of Mo-O-Mo bonds up to $50 \mathrm{~mol} \%$ of $\mathrm{MoO}_{3}$ which supports an assumption of no clusters formation in these glasses.

At the same time, Raman spectra clearly indicate completely different evolution of $\mathrm{WO}_{3}$ glass structures. The appearance of bands that corresponds to W-O-W bond at about 855 and $761 \mathrm{~cm}^{-1}$ for $\mathrm{WO}_{3}$ glasses in compositional range from 20 to $60 \mathrm{~mol} \%$ of $\mathrm{WO}_{3}$ suggests both that no $\mathrm{WO}_{4}$ tetrahedra are formed and that $\mathrm{WO}_{6}$ units are dominant in entire compositional 
region. Thus, at higher $\mathrm{WO}_{3}$ content, the closely linked $\mathrm{WO}_{6}$ units easily form clusters through $\mathrm{W}$ $\mathrm{O}-\mathrm{W}$ bonds. Finally, the incorporation of $\mathrm{WO}_{3}$ and $\mathrm{MoO}_{3}$ into zinc phosphate based glasses produces different glass network by forming or not clusters which are directly correlated with different behavior of DC conductivity. In particular, W-O-W bond formation due to progressive clustering of $\mathrm{WO}_{6}$ in Li-W and Na-W glasses acts as a crucial factor in significant enhancement of DC conductivity.

Considering another factor such is a fraction of molybdenum in $\mathrm{Mo}^{5+}$ and tungsten in $\mathrm{W}^{5+}$ valence state it should be mentioned that the $\mathrm{W}^{5+} / \mathrm{W}_{\text {tot }}$ ratio increases showing a plateau at about 20$30 \mathrm{~mol} \%$ of $\mathrm{WO}_{3}$ whereas $\mathrm{Mo}^{5+} / \mathrm{Mo}_{\text {tot }}$ ratio increases linearly for Na-Mo glasses. Ratio $\mathrm{Mo}^{5+} / \mathrm{Mo}_{\text {tot }}$ for Li-Mo glasses also increases having slightly higher values than that of Na-Mo glasses while an exception appeared for Li-50Mo showing an unexpected decrease. As illustrated in Tables 1 and 2, $\mathrm{Mo}^{5+} / \mathrm{Mo}_{\text {tot }}$ ratio reaches the highest value for $40 \mathrm{P}-60 \mathrm{Mo}$ glass suggesting that such a high content of molybdenum in $\mathrm{Mo}^{5+}$ valence state makes a significant contribution to the enhancement in DC conductivity. According to Poirier et al. findings ${ }^{15}$ the reduction in melt only occurs when W or Mo are in octahedral coordination indicating that $\mathrm{WO}_{6}$ and $\mathrm{MoO}_{6}$ octahedra exist in both tungsten and molybdenum glasses.

However, one of the most intriguing results of this study is exceptionally high electrical conductivity of the binary $40 \mathrm{P}-60 \mathrm{~W}$ glass in comparison to binary 40P-60Mo, Figure 4. Both glasses are purely polaronic conductors with the same molar percent of transition metal oxide. Hence it is expected that their conductivities are mainly dependent on the fractions of transition metal ions in different valence states, i.e. $\mathrm{W}^{5+} / \mathrm{W}_{\text {tot }}$ and $\mathrm{Mo}^{5+} / \mathrm{Mo}_{\text {tot }}$, Table 1 and 2 . However, 40-60W glass has drastically lower fraction of transitional metals in reduced form $\left(\mathrm{W}^{5+} / \mathrm{W}_{\text {tot }}=1.45\right.$ $\%)$ than 40P-60Mo glass $\left(\mathrm{Mo}^{5+} / \mathrm{Mo}_{\text {tot }}=37.04 \%\right)$ and despite this it exhibits approximately six orders of magnitude higher polaronic conductivity. This surprising result is most probably related to the 
structural characteristic of tungstate glasses, in particular clustering identified by Raman spectroscopy, Figure 2. It seems likely that the formation of tungstate clusters in this glass forms continuous $-\mathrm{W}^{5+}-\mathrm{O}-\mathrm{W}^{6+}-\mathrm{O}-\mathrm{W}^{5+}$ - bridges which consequently strongly increase the probability of polaron transfer resulting in a very high conductivity. In this context, it is clear that the structure has the most important role for polaronic transport in these glasses and not the parameter such as fraction of $\mathrm{W}^{5+}$ ions. $^{10}$

According to Arrhenius equation (2), the electrical conductivity has an exponential dependence on activation energy. Thus, it was expected that the decrease of DC conductivity in Li-W glasses containing up to $20 \mathrm{~mol} \%$ of $\mathrm{WO}_{3}$, is due to an increase in activation energy, $E_{\mathrm{DC}}$. However, Figure 8(a) shows that the activation energy for Li-W and Na-W glasses in compositional range up to 20 mol\% and $30 \mathrm{~mol} \%$ of $\mathrm{WO}_{3}$, respectively, has remained constant.

This behavior viewed on structurally local level could be that the mobility of $\mathrm{Li}^{+}$ions is reduced by both a reduction of $\mathrm{Li}_{2} \mathrm{O}$ content and reduction of movement through the pathways with higher energy barriers. This is consistent with the high values of activation energy of 105.7-104.4 $\mathrm{kJ} \mathrm{mol}^{-1}$ for Li-0TMO and Li-20W glasses, respectively. On the other hand, much lower activation energy of 88.4 and $84.2 \mathrm{~kJ} \mathrm{~mol}^{-1}$ was obtained for Na-0TMO and Na-30W glasses implying an easier transport of $\mathrm{Na}^{+}$ions along conduction pathways. This implies that the $\mathrm{Li}^{+}$ions have lower mobility in these glasses due to strong interactions with the structural units in the glass network. Also, with increasing temperature, the trend is reversed which indicates that the temperature increases the mobility of $\mathrm{Li}^{+}$ions much faster than $\mathrm{Na}^{+}$ones.

Furthermore, for Li-Mo and Na-Mo glasses the activation energy, $E_{\mathrm{DC}}$, and pre-exponential factor, $\sigma_{0}{ }^{*}$, show the same trend which is in correlation with changes in DC conductivity. This corroborates our previous conclusions that the modifications of the structure that occurs by the 
additions of $\mathrm{WO}_{3}$ and $\mathrm{MoO}_{3}$ are different for Li-W and Na-W glasses in comparison to Li-Mo and Na-Mo glasses.

\section{Conclusion}

The effect of compositional changes observed by the addition of $\mathrm{WO}_{3}$ and $\mathrm{MoO}_{3}$ in four glass series with the compositions: $\mathrm{xWO}_{3}-(30-0.5 \mathrm{x}) \mathrm{Li}_{2} \mathrm{O}-(30-0.5 \mathrm{x}) \mathrm{ZnO}-40 \mathrm{P}_{2} \mathrm{O}_{5}, \mathrm{xWO}_{3}-(30-0.5 \mathrm{x}) \mathrm{Na}_{2} \mathrm{O}-$ (30-0.5x) ZnO-40P $\mathrm{P}_{2} \mathrm{O}_{5}, \mathrm{xMoO}_{3}-(30-0.5 \mathrm{x}) \mathrm{Li}_{2} \mathrm{O}-(30-0.5 \mathrm{x}) \mathrm{ZnO}-40 \mathrm{P}_{2} \mathrm{O}_{5}$, and $\mathrm{xMoO}_{3}-(30-0.5 \mathrm{x}) \mathrm{Na}_{2} \mathrm{O}-$ $(30-0.5 \mathrm{x}) \mathrm{ZnO}-40 \mathrm{P}_{2} \mathrm{O}_{5},(\mathrm{x}=0-60 \mathrm{~mol} \%)$ on the electrical transport has been investigated. The main findings in this study are that the observed changes in DC conductivity for these mixed ionicpolaronic glasses strongly depend on the structural modifications occurred with the addition of $\mathrm{WO}_{3}$ and $\mathrm{MoO}_{3}$ content. The results reveal a different behavior of DC conductivity for either lithium or sodium glasses containing $\mathrm{WO}_{3}$ compared to the glasses with $\mathrm{MoO}_{3}$. The observed transition from ionic to polaronic conductivity exhibits a minimum at 20 and $30 \mathrm{~mol} \%$ of $\mathrm{WO}_{3}$ content in $\mathrm{DC}$ conductivity for Li-W and Na-W glasses probably due to varied nature of charge transfer. As can be seen in Raman spectra the initial addition of $\mathrm{WO}_{3}$ clearly shows the cross-linkage between phosphate chains and tungsten units via P-O-W connectivity supporting dominant ionic mobility of lithium and sodium ions. However, as the number of density of polarons increases and that of ions decreases, the conduction pathways are possibly obstructed for either the charge carriers causing an observed minimum in compositional region at 20-30 mol\% of $\mathrm{WO}_{3}$ content for $\mathrm{Li}-\mathrm{W}$ and $30-40$ mol\% of $\mathrm{WO}_{3}$ content for Na-W glasses was observed. Further addition of $\mathrm{WO}_{3}$ content sharply increases DC conductivity for almost six orders of magnitude for both $\mathrm{Na}-\mathrm{W}$ and Li-W series of glasses. Thus, at high $\mathrm{WO}_{3}$ content the clusters formed of $\mathrm{WO}_{6}$ octahedra via $\mathrm{W}-\mathrm{O}-\mathrm{W}$ bonds facilitates the mobility of polarons. Therefore, enhanced transport through $\mathrm{W}^{5+}-\mathrm{O}-\mathrm{W}^{6+}-\mathrm{O}-\mathrm{W}^{5+}$ bonds in clusters suggests easier pathways for electrons resulting in a significant increase of conductivity. On the other hand, for glasses containing high $\mathrm{MoO}_{3}$ content the structure is not 
characterized by the formation of clusters involved in Mo-O-Mo linkages. The addition of $\mathrm{MoO}_{3}$ content in entire compositional range produces the $\mathrm{P}-\mathrm{O}-\mathrm{Mo}$ bonds by inserting the $\mathrm{MoO}_{n}$ polyhedra into phosphate network forming a three-dimensional glass network. Such a glass structure allows movement of ions and polarons through the ionic and polaronic pathways independently.

Also, one of the interesting observations of this investigation is an exceptionally high DC conductivity of binary 40P-60W glass in comparison to the binary 40P-60Mo glass despite lower fraction of $\mathrm{W}^{5+} / \mathrm{W}_{\text {tot }}$. This extraordinary result is most probably related to the formation of tungsten clusters which forms continuous $\mathrm{W}^{5+}-\mathrm{O}-\mathrm{W}^{6+}-\mathrm{O}-\mathrm{W}^{5+}-\mathrm{O}-\mathrm{W}^{6+}$ bridges increasing consequently the probability of polaron transfer and resulting in high conductivity. Finally, the most important factor of polaronic transport in these glasses is the glass structure and not the parameters such as fraction of $\mathrm{W}^{5+}$ and $\mathrm{Mo}^{5+}$ ions.

\section{ACKNOWLEDGEMENTS}

This work was supported by the Croatian Science Foundation; project IP-09-2014-5863. D.P. would like to acknowledge the partial support of Croatian Science Foundation; project UIP-2014-09-8276. The authors are grateful to Jure Dragovic for his help in the magnetic measurements as well as to Dr. Diana Žilić for her help in determining g-factor. The authors acknowledge, with many thanks, Dr. Radha D. Banhatti for critically reading this manuscript. 


\section{REFERENCES}

[1] Liu M, Winnick J. Fundamental Issues in Modeling of Mixed Ionic-Electronic Conductors (MIECs). Solid State Ionics. 1999;118:11-21.

[2] Sakurai Y, Yamaki J. $\mathrm{V}_{2} \mathrm{O}_{5}-\mathrm{P}_{2} \mathrm{O}_{5}$ Glasses as Cathode for Lithium Secondary Battery. $J$. Electrochem. Soc. 1985;132:512-513.

[3] Tischendorf B, Otaigbe JU, Wiench JW, Pruski M, Sales BC. A study of Short and Intermediate Range Order in Zinc Phosphate Glasses. J. Non-Cryst. Solids. 2001;282:147-158.

[4] Kanwal N, Toms H, Hannon AC, Perras FA, Bryce DL, Karpukhina N, Abrahams I. Structure and Solubility Behaviour of Zinc Containing Phosphate Glasses. J. Mater. Chem. B. $2015 ; 3: 8842-8855$.

[5] Nassar AM, El Oker MM, Radwan SN, Nabhan E. Effect of MO (CuO, ZnO, and CdO) on the Compaction of Sodium Meta Phosphate Sealing Glass. Curr. Sci. Int. 2013;2:1-7.

[6] Al-Hawery AS. Infrared Absorption and Differential Scanning Calorimetry Studies of Sodium Tungstate Dihydrate Glasses Containing Iron Oxide. J. Phys. Chem. Solids. 1997;58:13251328.

[7] Mansingh A, Tandon RP. AC Conductivity of Tungsten Phosphate Glasses. Phys.Rev. B. $1980 ; 21: 4829-4839$. 
[8] Boudlich D, Bih L, El Hassane Archidi M, Haddad M, Yacoubi A, Nadiri A, Nadiri B. Infrared, Raman, and Electron Spin Resonance Studies of Vitreous Alkaline Tungsten Phosphates and Related Glasses. J. Am. Ceram. Soc. 2002;85:623-630.

[9] Austin IG, Mott NF. Polarons in Crystalline and Non-Crystalline Materials. Adv. Phy. $1969 ; 18: 41-102$.

[10] Šantić A, Banhatti RD, Pavić L, Ertap H, Yüksek M, Karabulut M, Moguš-Milanković A. Polaronic Transport in Iron Phosphate Glasses Containing $\mathrm{HfO}_{2}$ and $\mathrm{CeO}_{2}$. Phys. Chem. Chem. Phys. 2017;19:3999-4009.

[11] Bih L, El Omari L, Reau JM, Nadiri A, Yacoubi A, Haddad M. Electrical Properties of Glasses in the $\mathrm{Na}_{2} \mathrm{O}-\mathrm{MoO}_{3}-\mathrm{P}_{2} \mathrm{O}_{5}$ System. Materials Letters. 2001;50:308-317.

[12] Bih L, Abbas L, Nadiri A, Khemakhem H, Elouadi B. Investigations of Molybdenum Redox Phenomenon in $\mathrm{Li}_{2} \mathrm{O}-\mathrm{MoO}_{3}-\mathrm{P}_{2} \mathrm{O}_{5}$ Phosphate Glasses. J. Mol. Struct. 2008;872:1-9.

[13] Bazan C, Duffy JA, Ingram MD, Mallace MR. Conductivity Anomalies in TungstatePhosphate Glasses: Evidence for an Ion-Polaron Interaction?. Solid State Ionics. 1996;86-88:497501.

[14] Abbas L, Bih L, Nadiri A, El Amraoui Y, Mezzane D, Elouadi B. Properties of Mixed $\mathrm{Li}_{2} \mathrm{O}$ and $\mathrm{Na}_{2} \mathrm{O}$ Molybdenum Phosphate Glasses. J. Mol. Struct. 2008;876:194-198.

[15] Poirier G, Ottoboni FS, Cassanjes FC, Remonte A, Messadeq Y, Ribeiro SJL. Redox Behavior of Molybdenum and Tungsten in Phosphate Glasses. J. Phys. Chem. B. 2008;112:44814487.

[16] de Araujo CC, Strojek W, Zhang L, Eckert H, Poirier G, Riberio SJL, Messaddeq Y. Structural Studies of $\mathrm{NaPO}_{3}-\mathrm{WO}_{3}$ Glasses by Solid State NMR and Raman Spectroscopy. J. Mater. Chem. 2006;16:3277-3284. 
[17] Santagnelli SH, de Araujo CC, Strojek W, Eckert H, Poirier G, Riberio SJL, Messaddeq Y. Structural Studies of $\mathrm{NaPO}_{3}-\mathrm{MoO}_{3}$ Glasses by Solid-State Nuclear Magnetic Resonance and Raman Spectroscopy. J. Phys. Chem. B. 2007;111:10109-10117.

[18] Poirier G, Messadeq Y, Ribeiro SJL, Poulain M. Structural Study of Tungstate Fluorophosphate Glasses by Raman and X-ray Absorption Spectroscopy. J. Solid State Chem. 2005;178:1533-1538.

[19] Poirier G, Michalowicz A, Messadeq Y, Ribeiro, SJL. Local Order Around Tungsten Atoms in Tungstate Fluorophosphate Glasses by X-ray Absorption Spectroscopy. J. Non-Cryst. Solids 2005;351:3644-3648.

[20] Koudelka L, Šubčik J, Mošner P, Gregora I, Montagne L, Delevoye L. Glass-Forming Ability and Structure of Glasses in the $\mathrm{ZnO}-\mathrm{WO}_{3}-\mathrm{P}_{2} \mathrm{O}_{5}$ System. Phys. Chem. Glasses: Eur. J. Sci. Technol. B. 2012;53:79-85.

[21] Koudelka L, Rosslerova I, Holubova J, Mošner P, Montagne L, Revel B. Structural Study of $\mathrm{PbO}-\mathrm{MoO}_{3}-\mathrm{P}_{2} \mathrm{O}_{5}$ Glasses by Raman and NMR Spectroscopy. J. Non-Cryst. Solids. 2011;357:2816-2821.

[22] Brow RK. Review: the Structure of Simple Phosphate Glasses. J. Non-Cryst. Solids. 2000;263-264:1-28.

[23] Brow RK, Tallant DR, Myers ST, Phifer CC. The Short-Range Structure of Zinc Polyphosphate Glass. J. Non Cryst. Solids. 1995;191:45-55.

[24] Moguš-Milanković A, Gajović A, Šantić A, Day DE. Structure of Sodium Phosphate Glasses Containing $\mathrm{Al}_{2} \mathrm{O}_{3}$ and/or $\mathrm{Fe}_{2} \mathrm{O}_{3}$. Part I. J. Non-Cryst. Solids. 2001;289:204-213.

[25] Moguš-Milanković A, Pavić L, Reiss ST, Day DE, Ivanda M. Structural and Electrical Properties of $\mathrm{Li}_{2} \mathrm{O}-\mathrm{ZnO}-\mathrm{P}_{2} \mathrm{O}_{5}$ Glasses. J. Non-Cryst. Solids. 2010;356:715-719. 
[26] Šubčík J, Koudelka L, Mošner P, Montagne L, Tricot G, Delevoye L, Gregora I. GlassForming Ability and Structure of $\mathrm{ZnO}-\mathrm{MoO}_{3}-\mathrm{P}_{2} \mathrm{O}_{5}$ Glasses. J. Non-Cryst. Solids. 2010;356:25092516.

[27] Moguš-Milanković A, Sklepić K, Blažanović H, Mošner P, Vorokhta M, Koudelka L. Influence of Germanium Oxide Addition on the Electrical Properties of $\mathrm{Li}_{2} \mathrm{O}-\mathrm{B}_{2} \mathrm{O}_{3}-\mathrm{P}_{2} \mathrm{O}_{5}$ Glasses. J. Power Sources 2013;242:91-98.

[28] Garbarczyk JE, Machowski P, Wasiucionek M, Tykarski L, Bacewicz R, Aleksiejuk A. Studies of Silver-Vanadate-Phosphate Glasses by Raman, EPR and Impedance Spectroscopy Methods. Solid State Ionics. 2000;136-137:1077-1083.

[29] Sujatha B, Viswanatha R, Nagabushana H, Reddy CN. Electronic and Ionic Conductivity Studies on Microwave Synthesized Glasses Containing Transition Metal Ions. J. Mater. Res. Technol. 2017;6:7-12.

[30] Javier AE, Patel SN, Hallinan Jr DT, Srinivasan V, Balsara NP. Simultaneous Electronic and Ionic Conduction in a Block Copolymer: Application in Lithium Battery Electrodes. Angew. Chem. Int. Ed. 2011;50:9848-9851.

[31] Macdonald JR. Theory of Space $\square$ Charge Polarization and Electrode $\square$ Discharge Effects. $J$. Chem. Phys. 1973;58:4982-5001.

[32] Jamnik J, Maier J. Treatment of the Impedance of Mixed Conductors Equivalent Circuit Model and Explicit Approximate Solutions. J. Electrochem. Soc. 1999;146:4183-4188.

[33] Jamnik J, Maier J, Pejovnik S. A Powerful Electrical Network Model for the Impedance of Mixed Conductors. Electrochim. Acta 1999;44:4139-4145.

[34] Poirier G, Nalin M, Messadeq Y, Ribeiro SJL. Photochromic Properties of Tungstate-Based Glasses. Solid State Ionics. 2007;178:871-875. 


\section{$\underline{\text { Table captions }}$}

Table 1. Composition and experimental data for $\mathrm{xMO}_{3}-(30-0.5 \mathrm{x}) \mathrm{Li}_{2} \mathrm{O}-(30-0.5 \mathrm{x}) \mathrm{ZnO}-40 \mathrm{P}_{2} \mathrm{O}_{5}$ $(\mathrm{M}=\mathrm{W}, \mathrm{Mo})$ series of glasses.

Table 2. Composition and experimental data for $\mathrm{xMO}_{3}-(30-0.5 \mathrm{x}) \mathrm{Na}_{2} \mathrm{O}-(30-0.5 \mathrm{x}) \mathrm{ZnO}-40 \mathrm{P}_{2} \mathrm{O}_{5}$ $(\mathrm{M}=\mathrm{W}, \mathrm{Mo})$ series of glasses.

Table 3. DC conductivity, $\sigma_{\mathrm{DC}}$, activation energy, $E_{\mathrm{DC}}$, and pre-exponential factor, $\sigma_{0}{ }^{*}$, for all investigated series of glasses. 


\section{$\underline{\text { Figure captions }}$}

Fig. 1. Compositional dependence of the glass transition temperature, $\mathrm{T}_{\mathrm{g}}$, and density, $\rho$, for all investigated series of glasses (a) Na-W; (b) Na-Mo; (c) Li-W and (d) Li-Mo.

Fig. 2. Raman spectra of $\mathrm{xMO}_{3}-(30-0.5 \mathrm{x}) \mathrm{Li}_{2} \mathrm{O}-(30-0.5 \mathrm{x}) \mathrm{ZnO}-40 \mathrm{P}_{2} \mathrm{O}_{5}(\mathrm{M}=\mathrm{W}$, Mo) series of glasses.

Fig. 3. Conductivity spectra at different temperatures for (a) Li-10W glass and (b) Li-50W glass.

Fig. 4. DC conductivity trends of all investigated series of glasses (a) Li-W; (b) Na-W; (c) Li-Mo and (d) Na-Mo.

Fig. 5. Complex impedance plots for selected Na-W glasses (a) Na-10W, typical ionic plot; (b) Na-40W and (c) 40P-60W glass, typical polaronic plot.

Fig. 6. Compositional dependence of $\mathrm{W}^{5+} / \mathrm{W}_{\text {tot }}$ for both tungsten series of glasses (Li-W and NaW). Inset: Compositional dependence of $\mathrm{Mo}^{5+} / \mathrm{Mo}_{\text {tot }}$ for both molybdenum series of glasses (Li-Mo and Na-Mo).

Fig. 7. Arrhenius plots of temperature dependence of DC conductivity for (a) Li-W and (b) Li-Mo series of glasses.

Fig. 8. Compositional dependence of pre-exponential factor, $\sigma_{0} *$, and activation energy, $E_{\mathrm{DC}}$, for (a) Li-W and Na-W series and (b) Li-Mo and Na-Mo series of glasses. 


\section{$\underline{\text { Tables }}$}

Table 1. Composition and experimental data for $\mathrm{xMO}_{3}-(30-0.5 \mathrm{x}) \mathrm{Li}_{2} \mathrm{O}-(30-0.5 \mathrm{x}) \mathrm{ZnO}-40 \mathrm{P}_{2} \mathrm{O}_{5}(\mathrm{M}=$ W, Mo) series of glasses.

\begin{tabular}{cccccccc}
\hline & $\mathrm{WO}_{3}$ & $\mathrm{Li}_{2} \mathrm{O}$ & $\mathrm{ZnO}$ & $\mathrm{P}_{2} \mathrm{O}_{5}$ & $\begin{array}{c}\mathrm{T}_{\mathrm{g}} \\
(\mathrm{K})\end{array}$ & $\begin{array}{c}\rho \\
\left(\mathrm{g} \mathrm{cm}^{-3}\right)\end{array}$ & $\begin{array}{c}\mathrm{W}^{5+} / \mathrm{W}_{\text {tot }} \\
(\%)\end{array}$ \\
\hline $\mathrm{Li}-0 \mathrm{TMO}$ & 0 & 30 & 30 & 40 & 579 & 2.91 & 0 \\
\hline $\mathrm{Li}-10 \mathrm{~W}$ & 10 & 25 & 25 & 40 & 609 & 3.04 & 0.48 \\
$\mathrm{Li}-20 \mathrm{~W}$ & 20 & 20 & 20 & 40 & 614 & 3.20 & 0.66 \\
$\mathrm{Li}-30 \mathrm{~W}$ & 30 & 15 & 15 & 40 & 642 & 3.37 & 0.79 \\
$\mathrm{Li}-40 \mathrm{~W}$ & 40 & 10 & 10 & 40 & 716 & 3.69 & 1.39 \\
$\mathrm{Li}-50 \mathrm{~W}$ & 50 & 5 & 5 & 40 & 741 & 3.94 & 1.26 \\
\hline 40P-60W & 60 & 0 & 0 & 40 & 793 & 4.41 & 1.45 \\
\hline & $\mathrm{MoO}_{3}$ & $\mathrm{Li}_{2} \mathrm{O}$ & $\mathrm{ZnO}$ & $\mathrm{P}_{2} \mathrm{O}_{5}$ & & & $\mathrm{Mo}^{5+} / \mathrm{Mo}_{\text {tot }}$ \\
\hline Li-10Mo & 10 & 25 & 25 & 40 & 607 & 2.99 & 4.79 \\
$\mathrm{Li}-20 \mathrm{Mo}$ & 20 & 20 & 20 & 40 & 637 & 3.10 & 8.13 \\
$\mathrm{Li}-30 \mathrm{Mo}$ & 30 & 15 & 15 & 40 & 658 & 3.13 & 13.6 \\
$\mathrm{Li}-40 \mathrm{Mo}$ & 40 & 10 & 10 & 40 & 681 & 3.16 & 18.3 \\
$\mathrm{Li}-50 \mathrm{Mo}$ & 50 & 5 & 5 & 40 & 701 & 3.20 & 10.93 \\
\hline 40P-60Mo & 60 & 0 & 0 & 40 & 751 & 3.15 & 37.04 \\
\hline
\end{tabular}


Table 2. Composition and experimental data for $\mathrm{xMO}_{3}-(30-0.5 \mathrm{x}) \mathrm{Na}_{2} \mathrm{O}-(30-0.5 \mathrm{x}) \mathrm{ZnO}-40 \mathrm{P}_{2} \mathrm{O}_{5}(\mathrm{M}=$ W, Mo) series of glasses.

\begin{tabular}{cccccccc}
\hline Glass & $\mathrm{WO}_{3}$ & $\mathrm{Na}_{2} \mathrm{O}$ & $\mathrm{ZnO}$ & $\mathrm{P}_{2} \mathrm{O}_{5}$ & $\begin{array}{c}\mathrm{T}_{\mathrm{g}} \\
(\mathrm{K})\end{array}$ & $\begin{array}{c}\rho \\
\left(\mathrm{g} \mathrm{cm}^{-3}\right)\end{array}$ & $\begin{array}{c}\mathrm{W}^{5+} / \mathrm{W}_{\text {tot }} \\
(\%)\end{array}$ \\
\hline $\mathrm{Na}-0 \mathrm{TMO}$ & 0 & 30 & 30 & 40 & 576 & 2.93 & 0 \\
\hline $\mathrm{Na}-10 \mathrm{~W}$ & 10 & 25 & 25 & 40 & 615 & 3.26 & 0.47 \\
$\mathrm{Na}-20 \mathrm{~W}$ & 20 & 20 & 20 & 40 & 651 & 3.54 & 0.55 \\
$\mathrm{Na}-30 \mathrm{~W}$ & 30 & 15 & 15 & 40 & 689 & 3.79 & 0.54 \\
$\mathrm{Na}-40 \mathrm{~W}$ & 40 & 10 & 10 & 40 & 749 & 4.04 & 0.86 \\
$\mathrm{Na}-50 \mathrm{~W}$ & 50 & 5 & 5 & 40 & 774 & 4.24 & 1.20 \\
\hline 40P-60W & 60 & 0 & 0 & 40 & 793 & 4.41 & 1.45 \\
\hline & $\mathrm{MoO}_{3}$ & $\mathrm{Na}_{2} \mathrm{O}$ & $\mathrm{ZnO}$ & $\mathrm{P}_{2} \mathrm{O}_{5}$ & & & $\mathrm{Mo}^{5+} / \mathrm{Mo}_{\text {tot }}$ \\
& & & & & $(\%)$ \\
\hline $\mathrm{Na}-10 \mathrm{Mo}$ & 10 & 25 & 25 & 40 & 611 & 3.01 & 2.31 \\
$\mathrm{Na}-20 \mathrm{Mo}$ & 20 & 20 & 20 & 40 & 645 & 3.06 & 4.51 \\
$\mathrm{Na}-30 \mathrm{Mo}$ & 30 & 15 & 15 & 40 & 671 & 3.08 & 5.88 \\
$\mathrm{Na}-40 \mathrm{Mo}$ & 40 & 10 & 10 & 40 & 712 & 3.10 & 7.93 \\
$\mathrm{Na}-50 \mathrm{Mo}$ & 50 & 5 & 5 & 40 & 731 & 3.13 & 9.12 \\
\hline 40P-60Mo & 60 & 0 & 0 & 40 & 751 & 3.15 & 37.04 \\
\hline
\end{tabular}


Table 3. DC conductivity, $\sigma_{\mathrm{DC}}$, activation energy, $E_{\mathrm{DC}}$, and pre-exponential factor, $\sigma_{0}{ }^{*}$, for all investigated glasses.

\begin{tabular}{|c|c|c|c|}
\hline Glass & $\begin{array}{c}\sigma_{\mathrm{DC}} /(\Omega \mathrm{cm})^{-1} \\
\quad \pm 0.5 \% *\end{array}$ & $\begin{array}{c}E_{\mathrm{DC}} / \mathrm{kJ} \mathrm{mol}^{-1} \\
\quad \pm 0.5 \%\end{array}$ & $\begin{array}{c}\sigma_{0}{ }^{*} /(\Omega \mathrm{cm})^{-1} \mathrm{~K} \\
\pm 0.5 \%\end{array}$ \\
\hline \multicolumn{4}{|c|}{$\mathrm{WO}_{3}-\mathrm{Li}_{2} \mathrm{O}-\mathrm{ZnO}-\mathrm{P}_{2} \mathrm{O}_{5}$} \\
\hline Li-0TMO & $1.94 \times 10^{-13}$ & 105.7 & 7.88 \\
\hline $\mathrm{Li}-10 \mathrm{~W}$ & $6.73 \times 10^{-14}$ & 103.8 & 7.07 \\
\hline Li-20W & $9.34 \times 10^{-15}$ & 104.4 & 6.19 \\
\hline Li-30W & $1.99 \times 10^{-13}$ & 72.1 & 2.08 \\
\hline Li-40W & $1.30 \times 10^{-10}$ & 56.2 & 2.20 \\
\hline Li-50W & $1.01 \times 10^{-8}$ & 47.0 & 2.51 \\
\hline $40 \mathrm{P}-60 \mathrm{~W}$ & $4.26 \times 10^{-6}$ & 35.5 & 3.18 \\
\hline \multicolumn{4}{|c|}{$\mathrm{WO}_{3}-\mathrm{Na}_{2} \mathrm{O}-\mathrm{ZnO}-\mathrm{P}_{2} \mathrm{O}_{5}$} \\
\hline Na-0TMO & $7.87 \times 10^{-13}$ & 88.4 & 5.58 \\
\hline Na-10W & $1.44 \times 10^{-12}$ & 84.8 & 5.24 \\
\hline $\mathrm{Na}-20 \mathrm{~W}$ & $1.52 \times 10^{-12}$ & 83.4 & 5.03 \\
\hline $\mathrm{Na}-30 \mathrm{~W}$ & $5.84 \times 10^{-13}$ & 84.2 & 4.76 \\
\hline $\mathrm{Na}-40 \mathrm{~W}$ & $1.79 \times 10^{-11}$ & 60.0 & 2.08 \\
\hline Na-50W & $1.29 \times 10^{-8}$ & 46.8 & 2.60 \\
\hline \multicolumn{4}{|c|}{$\mathrm{MoO}_{3}-\mathrm{Li}_{2} \mathrm{O}-\mathrm{ZnO}-\mathrm{P}_{2} \mathrm{O}_{5}$} \\
\hline Li-10Mo & $6.92 \times 10^{-13}$ & 95.6 & 6.77 \\
\hline Li-20Mo & $1.58 \times 10^{-12}$ & 90.8 & 6.26 \\
\hline Li-30Mo & $1.27 \times 10^{-12}$ & 88.2 & 5.75 \\
\hline $\mathrm{Li}-40 \mathrm{Mo}$ & $9.70 \times 10^{-13}$ & 85.4 & 5.17 \\
\hline Li-50Mo & $1.75 \times 10^{-13}$ & 88.7 & 4.99 \\
\hline $40 \mathrm{P}-60 \mathrm{Mo}$ & $2.75 \times 10^{-11}$ & 54.4 & 1.21 \\
\hline \multicolumn{4}{|c|}{$\mathrm{MoO}_{3}-\mathrm{Na} 2 \mathrm{O}-\mathrm{ZnO}-\mathrm{P}_{2} \mathrm{O}_{5}$} \\
\hline Na-10Mo & $1.42 \times 10^{-12}$ & 85.2 & 5.27 \\
\hline $\mathrm{Na}-20 \mathrm{Mo}$ & $1.61 \times 10^{-12}$ & 83.0 & 4.97 \\
\hline $\mathrm{Na}-30 \mathrm{Mo}$ & $1.19 \times 10^{-12}$ & 82.1 & 4.76 \\
\hline $\mathrm{Na}-40 \mathrm{Mo}$ & $5.61 \times 10^{-13}$ & 83.1 & 4.55 \\
\hline $\mathrm{Na}-50 \mathrm{Mo}$ & $2.37 \times 10^{-13}$ & 79.6 & 3.45 \\
\hline
\end{tabular}

*values at $303 \mathrm{~K}$ 

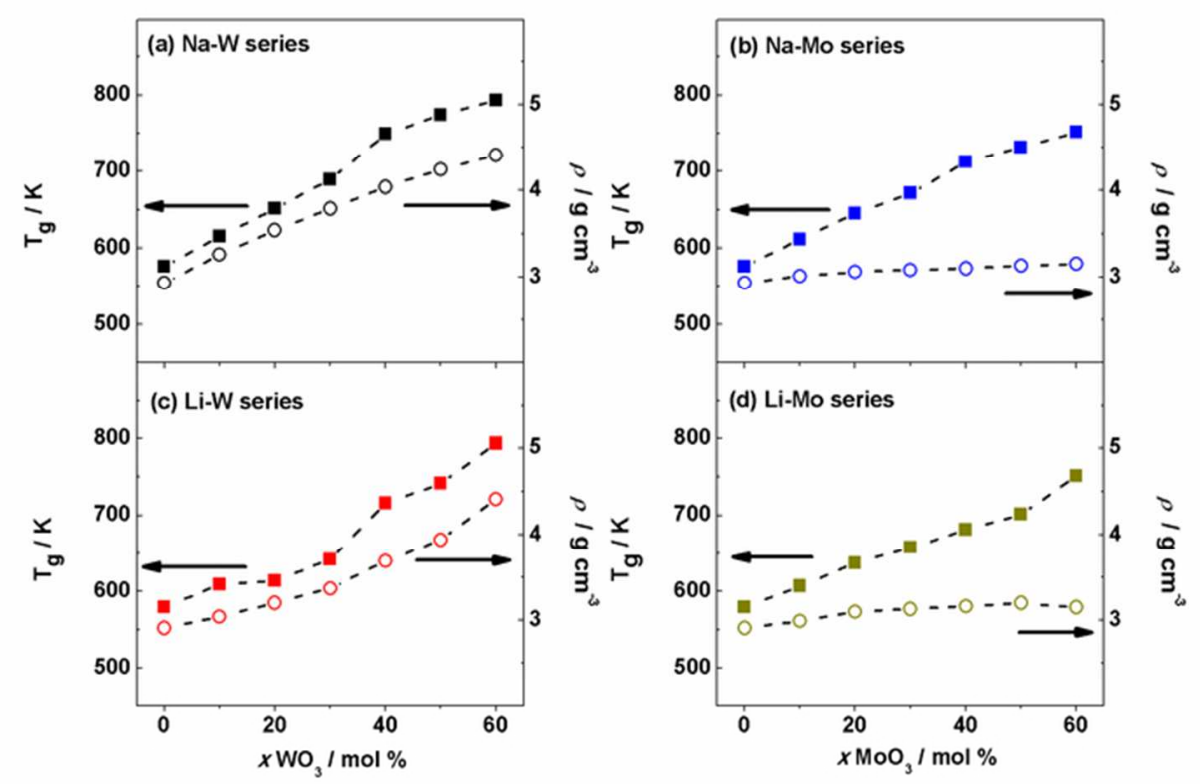

Figure 1. Compositional dependence of the glass transition temperature, $T_{g}$, and density, $\rho$, for all investigated series of glasses (a) Na-W; (b) Na-Mo; (c) Li-W and (d) Li-Mo.

$63 \times 44 \mathrm{~mm}(300 \times 300 \mathrm{DPI})$ 


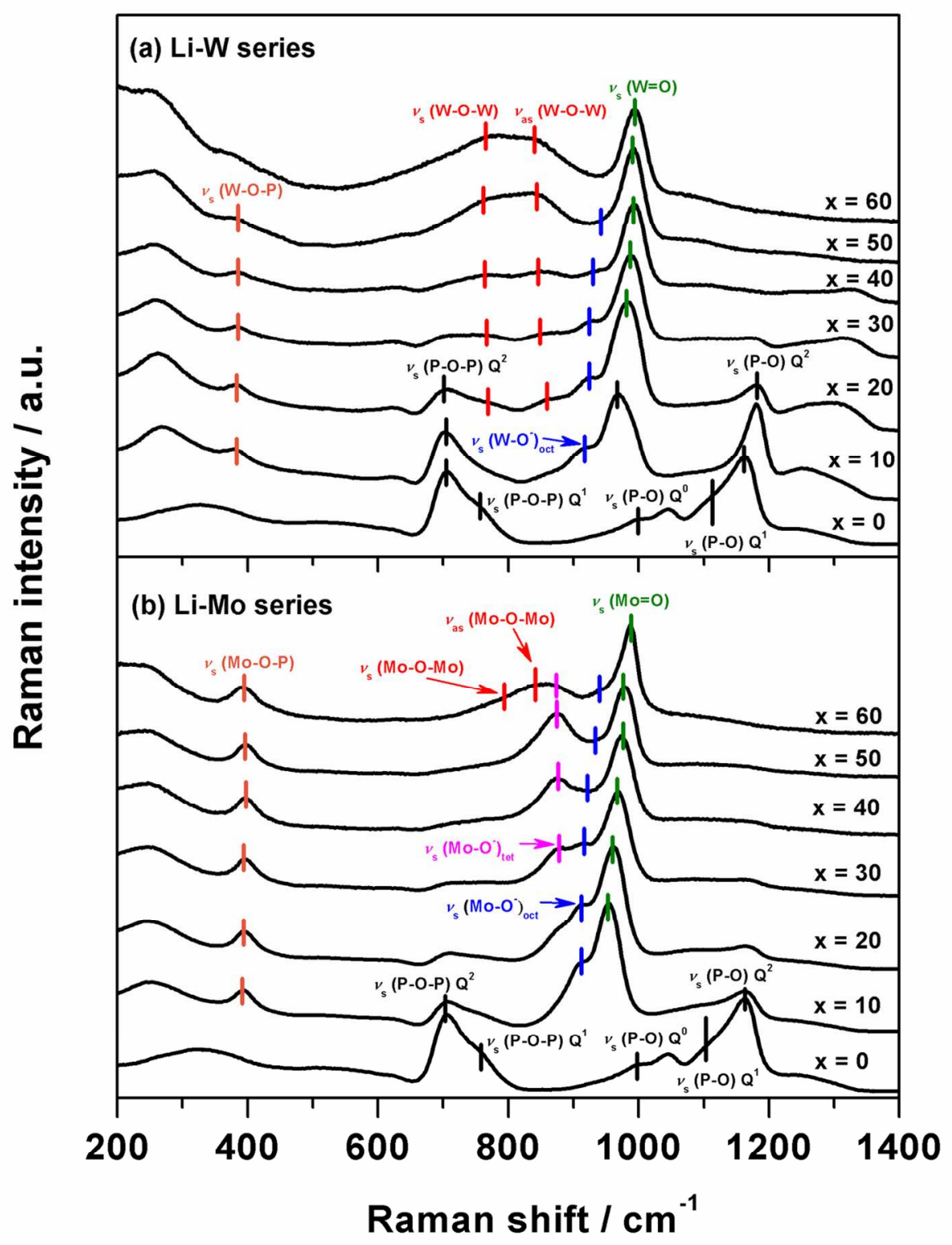

Figure 2. Raman spectra of $\mathrm{XMO}_{3}-(30-0.5 \mathrm{x}) \mathrm{Li} 2 \mathrm{O}-(30-0.5 \mathrm{x}) \mathrm{ZnO}-40 \mathrm{P}_{2} \mathrm{O}_{5}(\mathrm{M}=\mathrm{W}, \mathrm{Mo})$ series of glasses. $115 \times 149 \mathrm{~mm}(300 \times 300 \mathrm{DPI})$ 

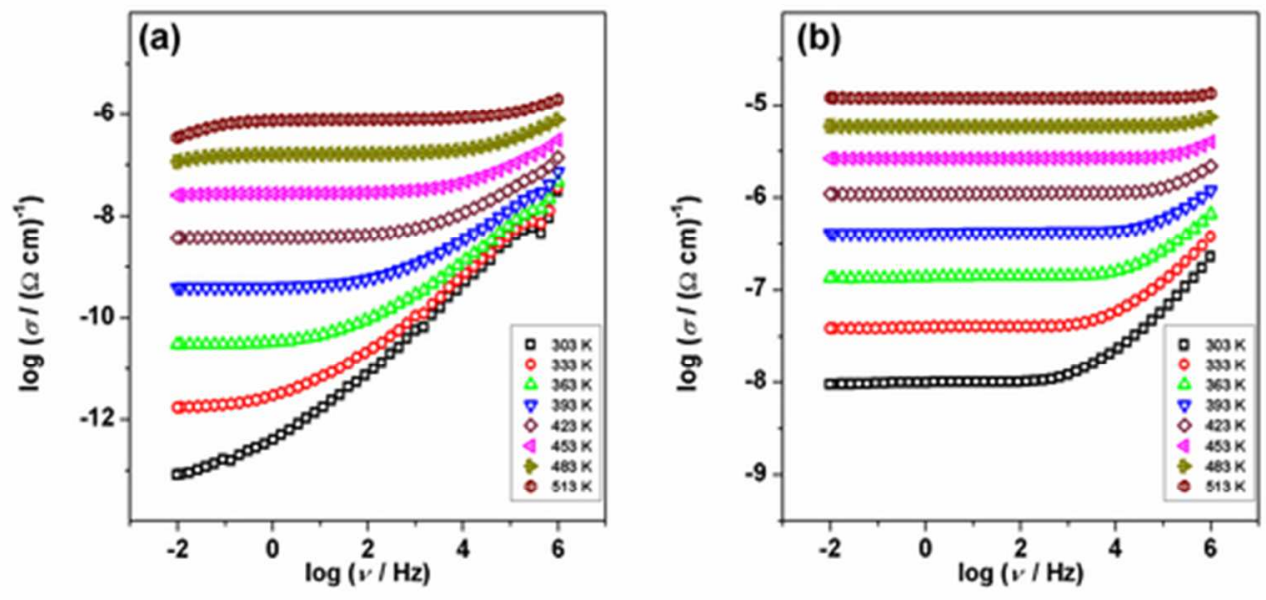

Figure 3. Conductivity spectra at different temperatures for (a) Li-10W glass and (b) Li-50W glass. $43 \times 21 \mathrm{~mm}(300 \times 300 \mathrm{DPI})$ 

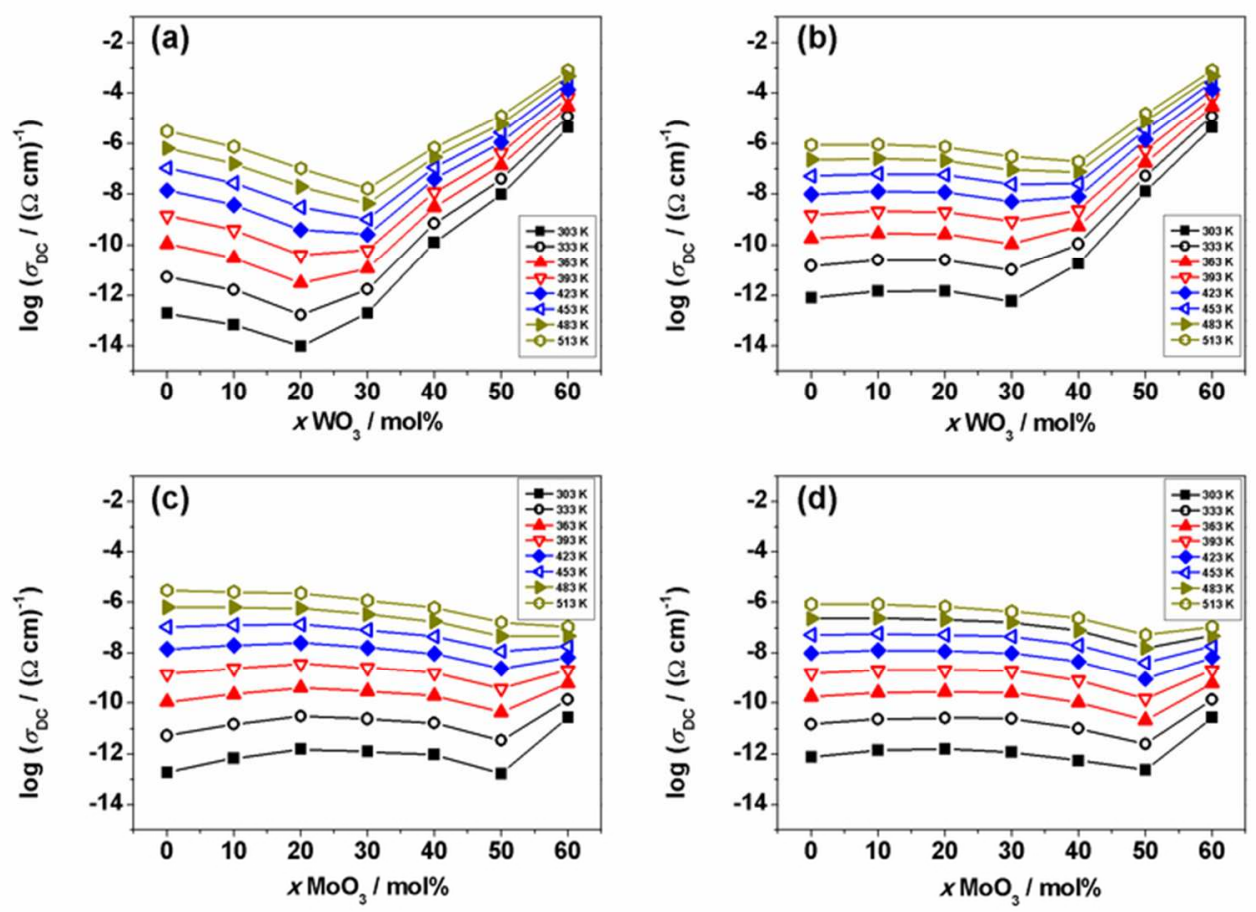

Figure 4. DC conductivity trends of all investigated series of glasses (a) Li-W; (b) Na-W; (c) Li-Mo and (d) Na-Mo. $66 \times 49 \mathrm{~mm}(300 \times 300 \mathrm{DPI})$ 
1

2

3

4

5

6

7

8

9

10

11

12

13

14

15

16

17

18

19

20

21

22

23

24

25

26

27

28

29

30

31

32

33

34

35

36

37

38

39

40

41

42

43

44

45

46

47

48

49

50

51

52

53

54

55

56

57

58

59

60

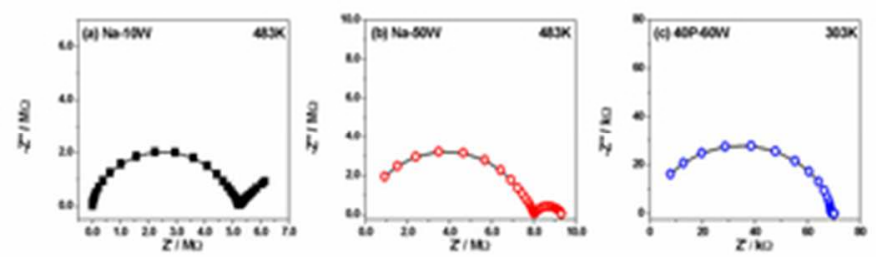

Figure 5. Complex impedance plots for selected Na-W glasses (a) Na-10W, typical ionic plot; (b) Na-40W and (c) 40P-60W glass, typical polaronic plot.

$28 \times 9 \mathrm{~mm}(300 \times 300 \mathrm{DPI})$ 


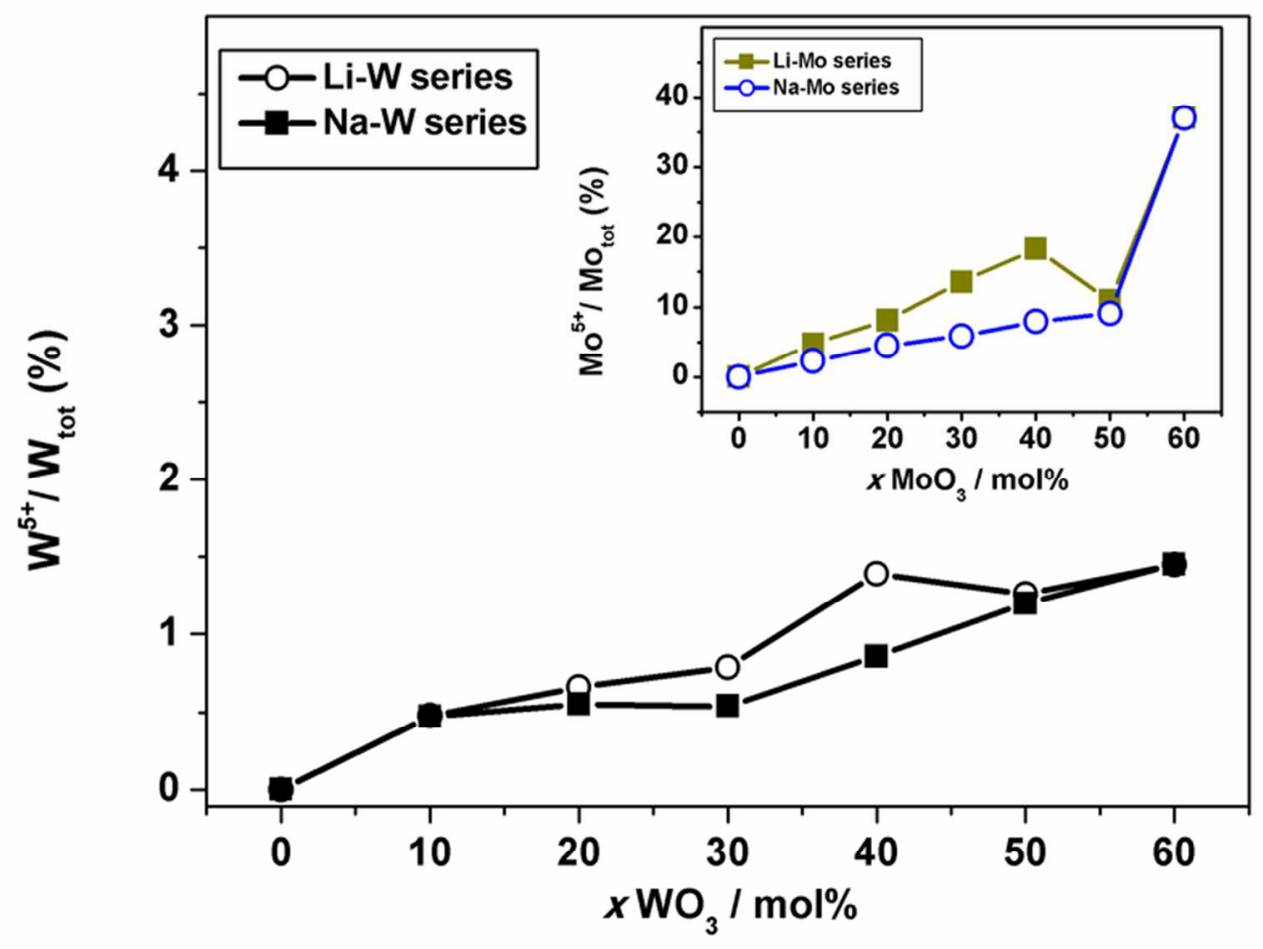

Figure 6. Compositional dependence of $\mathrm{W}^{5+} / \mathrm{W}_{\text {tot }}$ for both tungsten series of glasses ( $\mathrm{Li}-\mathrm{W}$ and $\mathrm{Na}-\mathrm{W}$ ). Inset: Compositional dependence of $\mathrm{Mo}^{5+} / \mathrm{Mo}_{\text {tot }}$ for both molybdenum series of glasses (Li-Mo and $\mathrm{Na}-\mathrm{Mo}$ ).

$68 \times 52 \mathrm{~mm}(300 \times 300 \mathrm{DPI})$ 


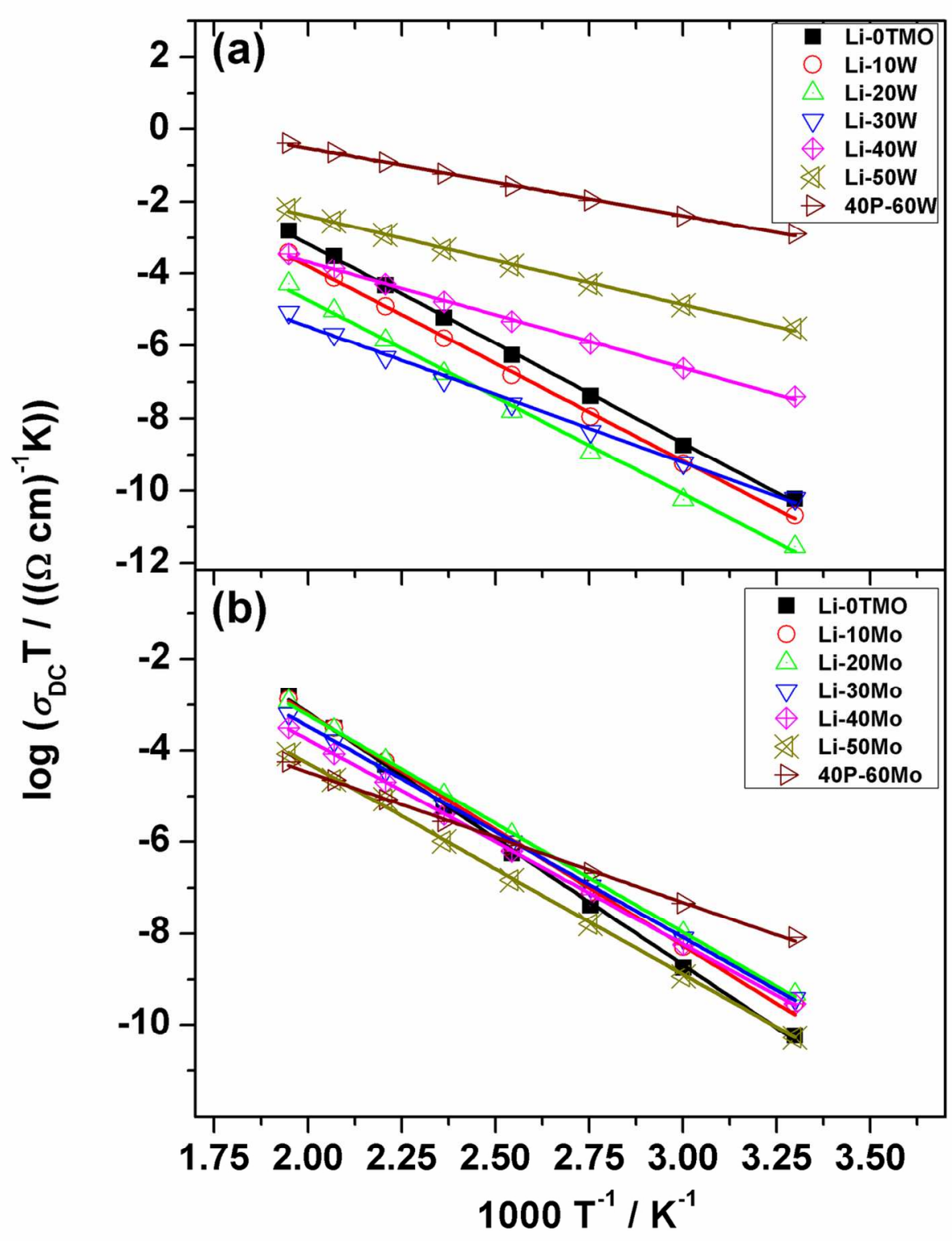

Figure 7. Arrhenius plots of temperature dependence of DC conductivity for (a) Li-W and (b) Li-Mo series of glasses.

$115 \times 147 \mathrm{~mm}(300 \times 300 \mathrm{DPI})$ 

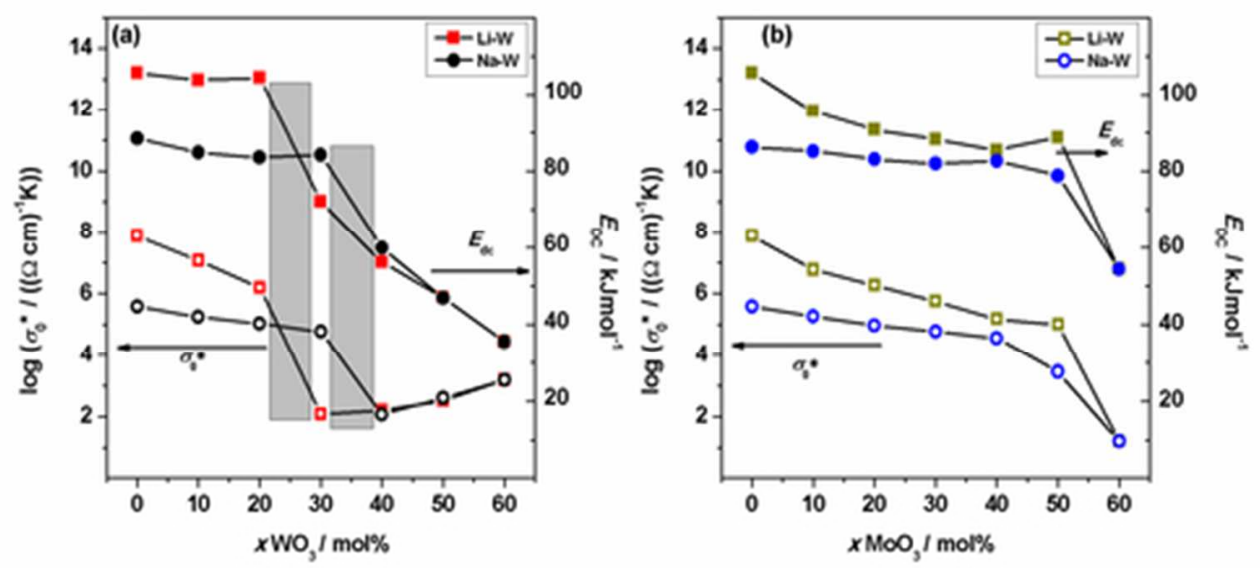

Figure 8. Compositional dependence of pre-exponential factor, $\sigma_{0}{ }^{*}$, and activation energy, $\mathrm{E}_{\mathrm{DC}}$, for (a) Li-W and Na-W series and (b) Li-Mo and Na-Mo series of glasses.

$41 \times 19 \mathrm{~mm}(300 \times 300$ DPI $)$ 


\title{
Supporting Information for the Article:
}

\section{Novel Insights Into the Electrical Transport}

\author{
Mechanism in Ionic-Polaronic Glasses \\ Juraj Nikolic ${ }^{a}$, Luka Pavić ${ }^{a}$, Ana Šantic ${ }^{a}$, Petr Mošner ${ }^{b,}$, Ladislav Koudelka ${ }^{b}$, Damir Pajic $^{c}$, \\ Andrea Moguš-Milankovićc ${ }^{a^{*}}$ \\ ${ }^{a}$ Division of Materials Chemistry, Ruđer Bošković Institute, 10000 Zagreb, Croatia \\ ${ }^{b}$ Department of General and Inorganic Chemistry, University of Pardubice, Faculty of Chemical \\ Technology, 53210 Pardubice, Czech Republic \\ ${ }^{\mathrm{c}}$ Department of Physics, Faculty of Science, University of Zagreb, 10000 Zagreb, Croatia \\ E-mail address: mogus@irb.hr
}




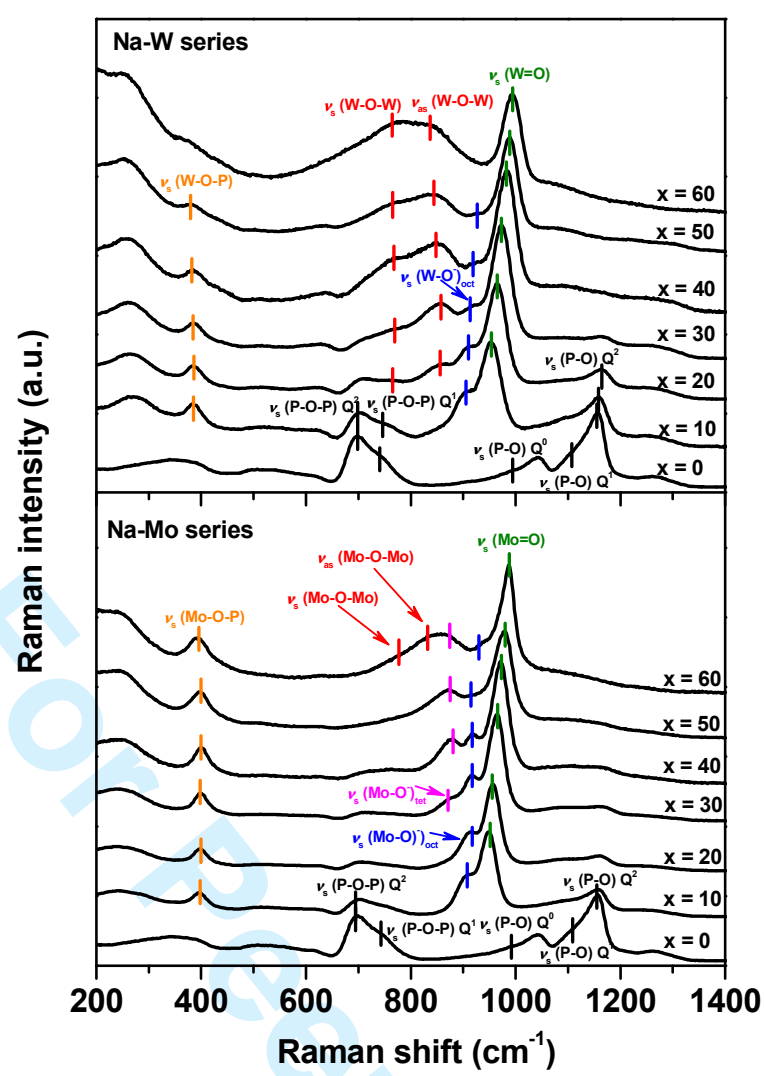

Figure S1. Raman spectra of $\mathrm{xMO}_{3}-(30-0.5 \mathrm{x}) \mathrm{Na}_{2} \mathrm{O}-(30-0.5 \mathrm{x}) \mathrm{ZnO}-40 \mathrm{P}_{2} \mathrm{O}_{5} \quad(\mathrm{M}=\mathrm{W}$, Mo) series of glasses. 

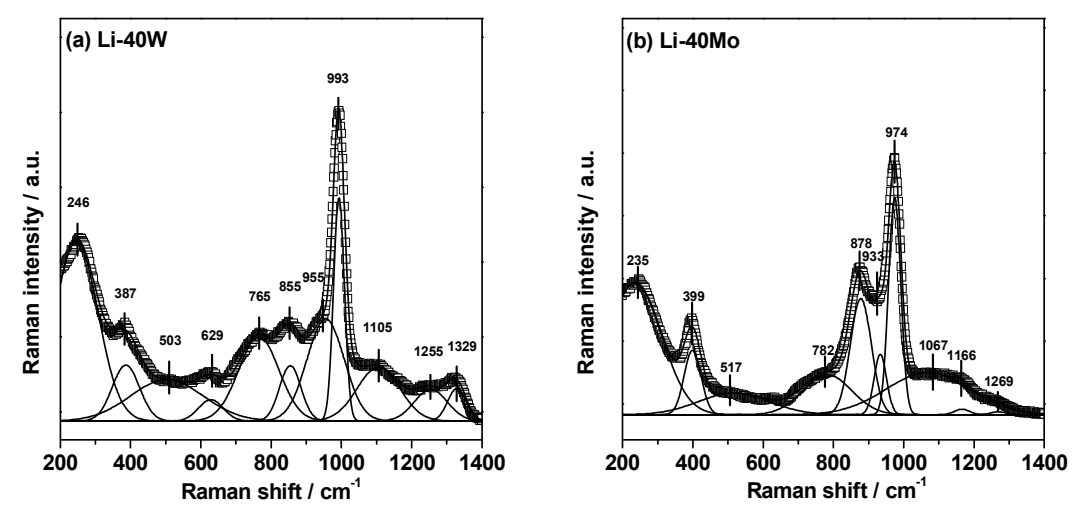

Figure S2. Examples of Raman spectra deconvolution of (a) Li-40W and (b) Li-40Mo. 
Table S1. Raman bands and their assignment.

\begin{tabular}{ccc}
\hline & & \\
Wavenumber $/ \mathrm{cm}^{-1}$ & Band & References \\
\hline $200-350$ & $\delta(\mathrm{O}-\mathrm{W}-\mathrm{O}), \delta(\mathrm{P}-\mathrm{O})$ & $20,22,23$ \\
$385-390$ & $v_{\mathrm{s}}(\mathrm{W}-\mathrm{O}-\mathrm{P})$ & 16,20 \\
$390-400$ & $v_{\mathrm{s}}(\mathrm{Mo}-\mathrm{O}-\mathrm{P})$ & $17,21,26$ \\
$450-650$ & $\delta(\mathrm{P}-\mathrm{O})$ & 22,23 \\
$700-715$ & $v_{\mathrm{s}}(\mathrm{P}-\mathrm{O}-\mathrm{P}) \mathrm{Q}^{2}$ & 22,23 \\
$740-775$ & $v_{\mathrm{s}}(\mathrm{P}-\mathrm{O}-\mathrm{P}) \mathrm{Q}^{1}$ & 22,23 \\
$760-780$ & $v_{\mathrm{s}}(\mathrm{W}-\mathrm{O}-\mathrm{W}), v_{\mathrm{s}}(\mathrm{Mo}-\mathrm{O}-\mathrm{Mo})$ & $16,17,20,21,26$ \\
$835-885$ & $v_{\text {as }}(\mathrm{W}-\mathrm{O}-\mathrm{W}), v_{\text {as }}(\mathrm{Mo}-\mathrm{O}-\mathrm{Mo})$ & $16,17,20,21,26$ \\
$870-890$ & $v_{\mathrm{s}}(\mathrm{Mo-O})_{\text {tet }}$ & $17,21,26$ \\
$910-970$ & $v_{\mathrm{s}}\left(\mathrm{W}-\mathrm{O}^{-}\right)_{\text {oct }}$ & 16,20 \\
$910-920$ & $v_{\mathrm{s}}\left(\mathrm{Mo}-\mathrm{O}^{-}\right)_{\text {oct }}$ & $17,21,26$ \\
$950-990$ & $v_{\mathrm{s}}\left(\mathrm{Mo}=\mathrm{O}^{-}\right)$ & 17 \\
$970-1000$ & $v_{\mathrm{s}}\left(\mathrm{W}=\mathrm{O}^{-}\right.$ & 16,20 \\
$1000-1010$ & $v_{\mathrm{s}}(\mathrm{P}-\mathrm{O}) \mathrm{Q}^{0}$ & 22,23 \\
$1040-1050$ & $v_{\mathrm{s}}(\mathrm{P}-\mathrm{O})_{\text {term }} \mathrm{Q}^{1}$ & 22,23 \\
$1080-1125$ & $v_{\mathrm{s}}(\mathrm{P}-\mathrm{O}) \mathrm{Q}^{1}$ & 22,23 \\
$1160-1175$ & $v_{\mathrm{s}}(\mathrm{P}-\mathrm{O}) \mathrm{Q}^{2}$ & 22,23 \\
$1200-1260$ & $v_{\text {as }}(\mathrm{P}-\mathrm{O}) \mathrm{Q}^{2}$ & 22,23 \\
$1280-1330$ & $v_{\mathrm{s}}(\mathrm{P}=\mathrm{O})$ & 22,23 \\
\hline
\end{tabular}

